\title{
Importance of the surface size distribution of erodible material: an improvement on the Dust Entrainment And Deposition (DEAD) Model
}

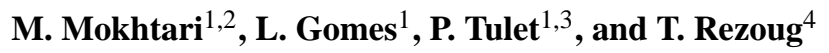 \\ ${ }^{1}$ CNRM/GAME, URA 1357, Météo-France, 42 av G. Coriolis, 31057 Toulouse, France \\ ${ }^{2}$ Office National de la Météorologie (ONM), Algeria \\ ${ }^{3}$ LACy, UMR 8105, Université de La Réunion 15 avenue René Cassin, 97715 Saint-Denis, France \\ ${ }^{4}$ Laboratoire des Sciences Aéronautiques (Blida), Algeria
}

Correspondence to: M. Mokhtari (m_morad06@yahoo.fr)

Received: 20 September 2011 - Published in Geosci. Model Dev. Discuss.: 10 November 2011

Revised: 6 April 2012 - Accepted: 10 April 2012 - Published: 3 May 2012

\begin{abstract}
This paper is based on dust aerosol cycle modelling in the atmospheric model ALADIN (Aire Limitée Adaptation dynamique Développement InterNational) coupled with the EXternalised SURFace scheme SURFEX. Its main goal is to create an appropriate mineral dust emission parameterization compatible with the global database of land surface parameters ECOCLIMAP, and the Food and Agriculture Organization (FAO) soil type database in SURFEX. An improvement on the Dust Entrainment And Deposition scheme (DEAD) is proposed in this paper by introducing the geographical variation of surface soil size distribution, the Marticorena and Bergametti (1995) formulation of horizontal saltation flux and the Shao et al. (1996) formulation of sandblasting efficiency $\alpha$. To show the importance of the modifications introduced in the DEAD, both sensitivity and comparative studies are conducted in 0 dimensions (0D) and then in 3 dimensions (3-D) between the old DEAD and the new DEAD. The results of the 0-D simulations indicate that the revised DEAD scheme represents the dust source emission better, particularly in the Bodélé depression, and provides a reasonable friction threshold velocity. In 3-D simulations, small differences are found between the DEAD and the revised DEAD for the simulated Aerosol Optical Depth (AOD) compared with the AErosol RObotic NETwork (AERONET) photometer measurements available in the African Monsoon Multidisciplinary Analyses (AMMA) databases. For the surface concentration, a remarkable improvement is noted for the revised DEAD scheme.
\end{abstract}

\section{Introduction}

The impacts of mineral dust aerosols on climate and environment have increased substantially in recent decades, creating a need to better understand and eventually predict the atmospheric dust cycle, which is involved in direct radiative forcing processes (Tegen et al., 1996), nutrient transport (Martin, 1990; Swap et al., 1992), land-use change (Nicholson et al., 1998) and ecosystem health (Prospero, 1999; Shinn et al., 2000). With this in mind, several numerical dust models have been developed (Tegen and Fung, 1994; Nickovic and Dobricic, 1996; Nickovic et al., 2001) and used for studying dust emissions and transport. The first difficulty in evaluating the impacts of dust aerosols on climate and environment is to correctly determine their atmospheric concentration. To do this, it is necessary to rigorously represent emissions in order to predict their distribution in time and space and their intensity/frequency.

The mineral dust emissions from arid and semi-arid areas are strongly influenced by soil and surface characteristics. The soil and surface features control three major processes of dust production: the erosion threshold wind velocity, the wind shear-stress acting on the erodible surface, and the capability of the soil to release fine dust particles. Recently, many dust emission schemes have been developed in order to provide an explicit representation of the mineral dust emission processes and the influence of soil and surface features. These models are frequently classified according to their representation of mobilization. Two categories of models 


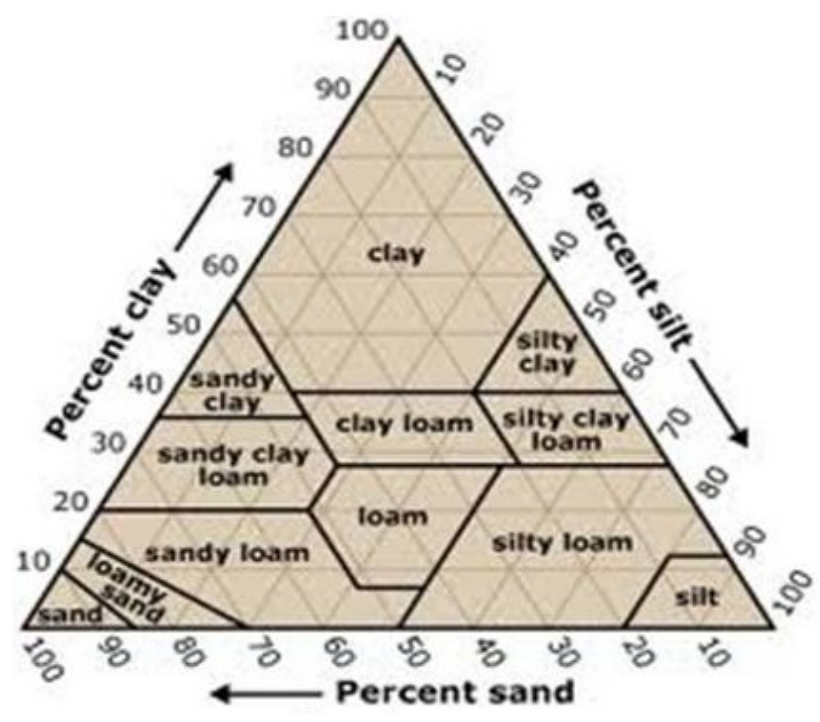

Fig. 1. Sand/clay/silt triangle of texture composition according USDA (1998).

are distinguished (Zender et al., 2003). The simpler class, named bulk mobilization schemes, calculate mobilization processes in terms of the third or fourth power of the wind friction speed, and include those of Tegen and Fung (1994), Mahowald et al. (1999), and Perlwitz et al. (2001). The complex class uses complete microphysical specification of the erodible environment to predict the saltation mass flux and resulting sandblasted dust emissions (Marticorena and Bergametti, 1995; Shao et al., 1996; Shao, 2001). These schemes have given promising results at the regional scale (Shao and Leslie, 1997; Marticorena et al., 1997). Unfortunately, many inputs for these fully microphysical schemes remain unknown. DEAD is an intermediate scheme in terms of complexity, developed by Zender et al. (2003). The DEAD1.1.15 version used in Zender et al. (2003a) and Zender et al. (2003b) (http://dust.ess.uci.edu/dead/) was coupled with the externalised surface scheme SURFEX (Noilhan and Mahfouf, 1996) by Grini et al. (2006). This version assumes that the soil texture is globally uniform and contains an abundance of particles having a diameter of $75 \mu \mathrm{m}$, the optimal size for saltation (Zender et al., 2003). The saltation flux calculated for this type of particle is weighted by the fraction of sand available in the soil (Grini et al., 2006). The transfer function between the horizontal saltation flux and the vertical mass flux $(\alpha)$ is calculated by the Marticorena and Bergametti (1995) relationships (hereinafter referred to as MaB95). DEAD uses a uniform value of clay fraction $\left(M_{\text {clay }}=0.2\right)$ to determine the sandblasting mass efficiency $\alpha$ (Zender et al., 2003).

Nevertheless, some important processes able to influence dust emission are ignored in the original version of DEAD: geographic variation of the surface soil size distribution (Marticorena et al., 1997) and size-dependent energy thresh-
Table 1. Soil texture classification following USDA (1998).

\begin{tabular}{llll}
\hline & Soil texture & & Soil Texture \\
\hline 1 & Sand & 7 & Silty clay loam \\
2 & Loamy sand & 8 & Clay loam \\
3 & Sandy loam & 9 & Sandy clay \\
4 & Silt loam & 10 & Silty clay \\
5 & Loam & 11 & Clay \\
6 & Sandy clay loam & 12 & Silt \\
\hline
\end{tabular}

olds for particles released during sandblasting (Alfaro and Gomes, 2001). This information can be supplied in the SURFEX scheme using the ECOCLIMAP database (Masson et al., 2003), which provides information on the erodible fraction represented by the covers COVER004 and COVER005, relating to bare and rock soil, and the FAO database, which contains information on the sand and clay fractions, allowing a classification of the soil textures (Masson et al., 2003). In this paper, a modification of the dust emission scheme (DEAD) is proposed and consists of introducing geographic variation of the surface soil size distribution, the MaB95 relationship in the horizontal saltation flux, and Shao et al.'s (1996) formulation of sandblasting efficiency. To evaluate the performance of the modification introduced in the DEAD scheme, two experiments were carried out in 0-D and 3-D with the old and the new schemes. The 3-D experiment was performed within the atmospheric model ALADIN (Bubnová et al., 1995) coupled with SURFEX. This experiment was run to simulate the 7-13 March 2006 west African dust storm. The results are compared with the local AOD and mass concentration measurements available from the AMMA database.

The paper is organised as follows: Sect. 2 summarizes the revised DEAD scheme which is introduced into SURFEX. Section 3 describes the 0-D and 3-D sensitivity and comparative studies between the old and the new schemes, and Sect. 4 presents concluding remarks with a summary of the main results.

\section{Update of the dust emission scheme coded in SURFEX}

The representation of dust emission processes is very important in a dust model. It depends on wind conditions, surface characteristics and soil type. The revised DEAD scheme is based on parameterizations of soil aggregate saltation and sandblasting processes. The main steps for this scheme are: the calculation of the soil aggregate size distribution for each model grid cell, the calculation of a threshold friction velocity leading to erosion and saltation processes, the calculation of the horizontal saltating soil aggregate mass flux and, finally, the calculation of the vertical transportable dust particle mass fluxes generated by the saltating aggregates. 

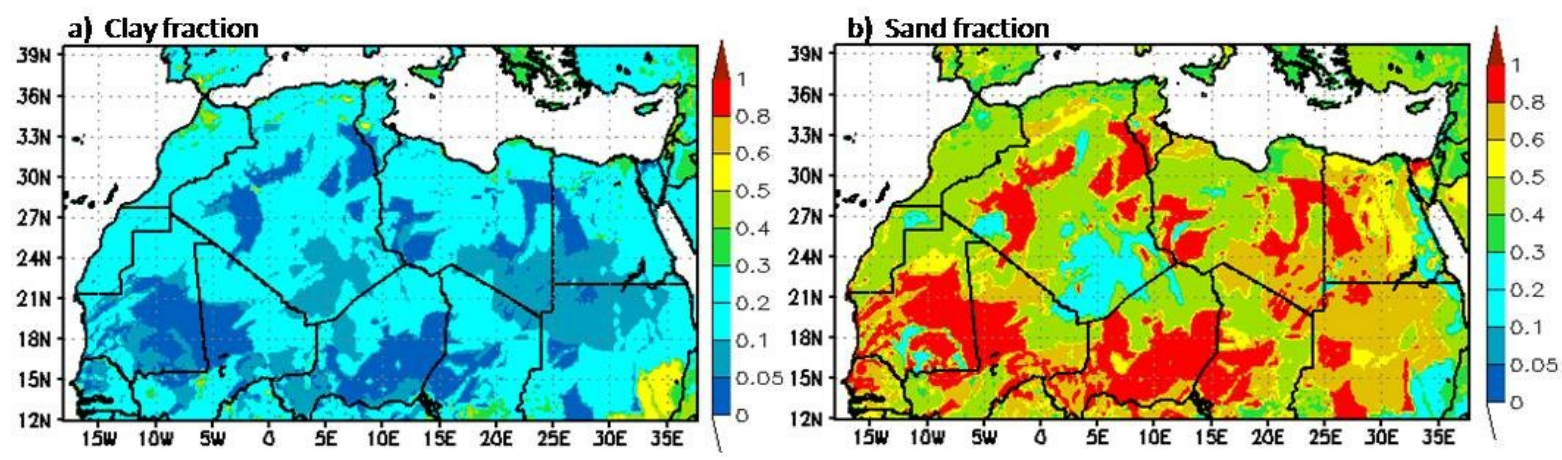

Fig. 2. Percentage of clay (a) and sand (b) for northern Africa according to FAO databases.

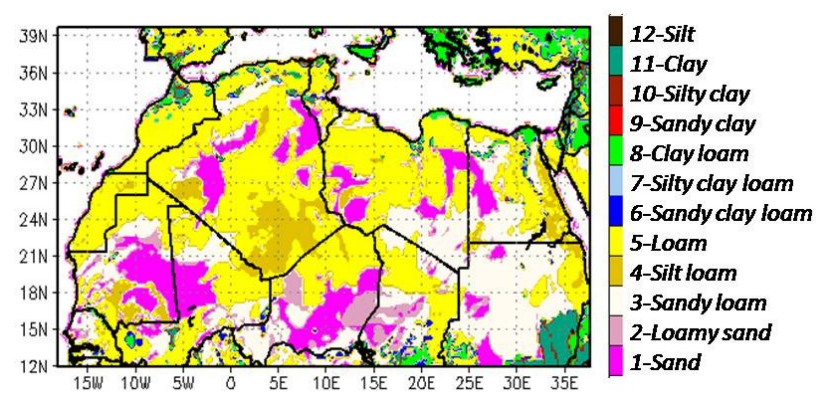

Fig. 3. Soil texture map for northern Africa obtained by combining the USDA sand/clay/silt textural triangle and proportions of clay and sand provided by FAO databases.

\subsection{Soil texture methodology}

Soil texture is the result of physicochemical processes acting on rocks and minerals that have decomposed in situ or that have been deposited by wind, water or ice (after transportation). It is influenced by external factors like climate, topography, and living organisms. A knowledge of the soil texture is necessary to determine the fine particle emission potential of the soil and to check the soil water content. In order to characterize the erodible fraction of different types of soils, soil aggregate distributions are provided to the DEAD scheme. These distributions use the USDA (United States Department of Agriculture) textural classification (Table 1), for which different types of soil are classified according to an index referring to the classic sand/clay/silt triangle of texture composition (Fig. 1) (Buckley, 2001). Sand particles range in size from $0.05-2.0 \mathrm{~mm}$, silt ranges from $0.002-0.05 \mathrm{~mm}$, and clay is made up of particles less than $0.002 \mathrm{~mm}$ in diameter. Gravel or rocks greater than $2 \mathrm{~mm}$ in diameter are not considered when determining texture. The combined amounts of clay and sand in the SURFEX scheme are provided by the global FAO database at $10 \mathrm{~km}$ resolution (Masson et al., 2003). The proportions of clay and sand are shown in Fig. 2a and Fig. 2b, respectively, for northern Africa. The silt frac- tion is the portion that completes the sand and clay so that the sum of the three portions (clay, sand and silt) is equal to 1.

Once the percentages of sand, clay, and silt in the soil are known, the textural class can be read from the textural triangle. For example, a soil with $40 \%$ sand, $40 \%$ silt, and $20 \%$ clay would be classified as a loam. Thus, a map of soil texture can be created (Fig. 3).

The analysis of Fig. 3 shows that northern Africa is dominated by a medium texture represented by loamy and sandy loam soil. These types of soil correspond to the Aridisols and Entisols in the Global soil region map classification (USDA/NRCS 1999). In second position, we find sand and loamy sand soil; these soils correspond to shifting sands in the USDA classification (USDA/NRCS 1999). Regions with such soils are essentially composed of a continuous coarse sand substratum, producing stable dunes made of coarse sands (median diameter $700 \mu \mathrm{m}$ ) and active dunes made of fine sands (median diameter $250 \mu \mathrm{m}$ ) (Callot et al., 2000). Silt loam occupies the major part of Hoggar and the extreme east of Egypt towards the Red Sea. Finally, clay and clay loam occupies a very limited area in northern Africa especially near the Nile river and the south-eastern Sudan.

\subsection{Soil aggregate distribution}

A three-mode log-normal soil mass size distribution $M^{T}\left(D_{p}\right)$ is related with each texture class following Zobler (1986):

$$
\frac{d M^{T}\left(D_{p}\right)}{d \ln \left(D_{p}\right)}=\sum_{j=1}^{n} \frac{M_{j}^{T}}{\sqrt{2 \cdot \pi} \cdot \ln \left(\sigma_{j}^{T}\right)} \cdot \exp \frac{\left(\ln D_{p}-\ln D_{\text {medj }}^{T}\right)^{2}}{-2 \cdot \ln ^{2} \sigma_{j}^{T}}
$$

where $j$ refers to the mode, $T$ refers to the texture, $M_{j}^{T}$ is the mass fraction of particles for mode $j, D_{\text {medj }}^{T}$ is the mass median diameter, and $\sigma_{j}^{T}$ is the geometric standard deviation. 
Table 2. The 12 basic USDA soil texture indices and corresponding soil aggregate size distribution parameters.

\begin{tabular}{lcccccccccc}
\hline & \multicolumn{3}{c}{ Mode 1 } & \multicolumn{3}{c}{ Mode 2 } & \multicolumn{5}{c}{ Mode 3 } \\
\hline soil type & $\%$ & $\mathrm{D}_{\text {med }}(\mu \mathrm{m})$ & $\sigma$ & $\%$ & $\mathrm{D}_{\text {med }}(\mu \mathrm{m})$ & $\sigma$ & $\%$ & $\mathrm{D}_{\text {med }}(\mu \mathrm{m})$ & $\sigma$ \\
\hline Sand & 90 & 1000 & 1.6 & 10 & 100 & 1.7 & 0 & 10 & 1.8 \\
Loamy sand & 60 & 690 & 1.6 & 30 & 100 & 1.7 & 10 & 10 & 1.8 \\
Sandy loam & 60 & 520 & 1.6 & 30 & 100 & 1.7 & 10 & 5 & 1.8 \\
Silt loam & 50 & 520 & 1.6 & 35 & 100 & 1.7 & 15 & 5 & 1.8 \\
Loam & 35 & 520 & 1.6 & 50 & 75 & 1.7 & 15 & 2.5 & 1.8 \\
Sandy clay loam & 30 & 210 & 1.7 & 50 & 75 & 1.7 & 20 & 2.5 & 1.8 \\
Silt clay loam & 30 & 210 & 1.7 & 50 & 50 & 1.7 & 20 & 2.5 & 1.8 \\
Clay loam & 20 & 125 & 1.7 & 50 & 50 & 1.7 & 30 & 1 & 1.8 \\
Sandy clay & 65 & 100 & 1.8 & 0 & 10 & 1.8 & 35 & 1 & 1.8 \\
Silty clay & 60 & 100 & 1.8 & 0 & 10 & 1.8 & 40 & 0.5 & 1.8 \\
Clay & 50 & 100 & 1.8 & 0 & 10 & 1.8 & 50 & 0.5 & 1.8 \\
Silt & 45 & 520 & 1.6 & 40 & 75 & 1.7 & 15 & 2.5 & 1.8 \\
\hline
\end{tabular}

Table 2 shows the mass fraction of the mode $j M_{j}^{T}$, the mass median diameter $D_{\text {medj }}^{T}$, the standard deviation $\sigma_{j}^{T}$, and the soil texture composition used to characterize each textural class (Zakey et al., 2006).

Following MaB95, the surface covered by each soil particle, with diameter $D_{p}$, is assimilated to its basal surface. Thus a size distribution of the basal surface can be computed from the mass distribution, assuming spherical particles with the same density $\rho_{p}$ :

$d S^{T}\left(D_{p}\right)=\frac{d M^{T}\left(D_{p}\right)}{\frac{2}{3} \cdot \rho_{p} \cdot D_{p}}$.

The total basal surface $S_{\text {total }}$ is

$S_{\text {total }}=\int_{D_{p}} d S^{T}\left(D_{p}\right) d D_{p}$

and the normalized continuous relative distribution of basal surfaces $d S_{\mathrm{rel}}^{T}\left(D_{p}\right)$ is

$d S_{\text {rel }}^{T}\left(D_{p}\right)=\frac{d S^{T}\left(D_{p}\right)}{S_{\text {total }}}$.

In our study, the process adopted to calculate the relative surface area for each soil particle is based on a soil sample containing 1000 particles with diameters in the range of 0.01 $<D_{p}<2000 \mu \mathrm{m}$. So, all soil particles that contribute to saltation and sandblasting processes are considered.

In order to increase the computation efficiency of the model and reduce the number of variables related to soil particles, the particles of our sample soil were divided into four populations according to their size: (a) clay size $D_{p}<2 \mu \mathrm{m}$, (b) small silt size $2 \mu \mathrm{m}<D_{p}<10 \mu \mathrm{m}$, (c) large silt size $10 \mu \mathrm{m}<D_{p}<60 \mu \mathrm{m}$, and (d) sand size $D_{p}>60 \mu \mathrm{m}$. The average relative surface area of each population was calculated according to the relative areas covered by the soil particles in the four size domains considered. The average relative surface area of each of the four populations $d S_{\text {rel }}\left(D_{\text {bin }}\right)$ is shown in Fig. 4 superimposed with the cover "COVER004" related to the fraction of erodible surface.

Thus, the potential dust source map obtained for the revised DEAD version is represented by the total of the average relative surface areas of the four populations (Fig. 5).

\subsection{Dust mobilization}

The physical basis of the revised DEAD scheme is globally the MaB95 scheme, where dust is calculated as a function of saltation and sandblasting. Fine soil particles are not directly mobilized by wind but they are injected into the atmosphere during sandblasting caused by saltation bombardment. According to Zender et al. (2003), the optimal size for saltation is $D_{0}=75 \mu \mathrm{m}$. Thus, dust mobilization starts when the friction velocity $u_{*}$ exceeds a threshold value named the threshold friction velocity $u_{* t}$. This threshold friction velocity was parameterized as in MaB95 and was obtained for a particle $D_{0}$ of about $75 \mu \mathrm{m}$ in diameter. Following MaB95, we assume that all soils in the erodible region contain particles of size $D_{0}$. The threshold friction velocity depends on drag partitioning (MaB95) and soil moisture (Fécan et al., 1999).

The drag partition ratio $f_{d}$ is calculated (MaB95) as:

$f_{d}=\left[1-\left(\frac{\ln \left(Z_{0} / Z_{0 s}\right)}{\ln \left\{0.35\left[\left(0.1 / Z_{0 s}\right)^{0.8}\right]\right\}}\right)\right]^{-1}$

where $Z_{0}(\mathrm{~cm})$ and $Z_{0 s}(\mathrm{~cm})$ are the roughness length for momentum and the smooth roughness length, respectively.

The smooth roughness length $Z_{0 s}$ is estimated following MaB95:

$Z_{0 s}=D_{\text {med }} / 30$ 

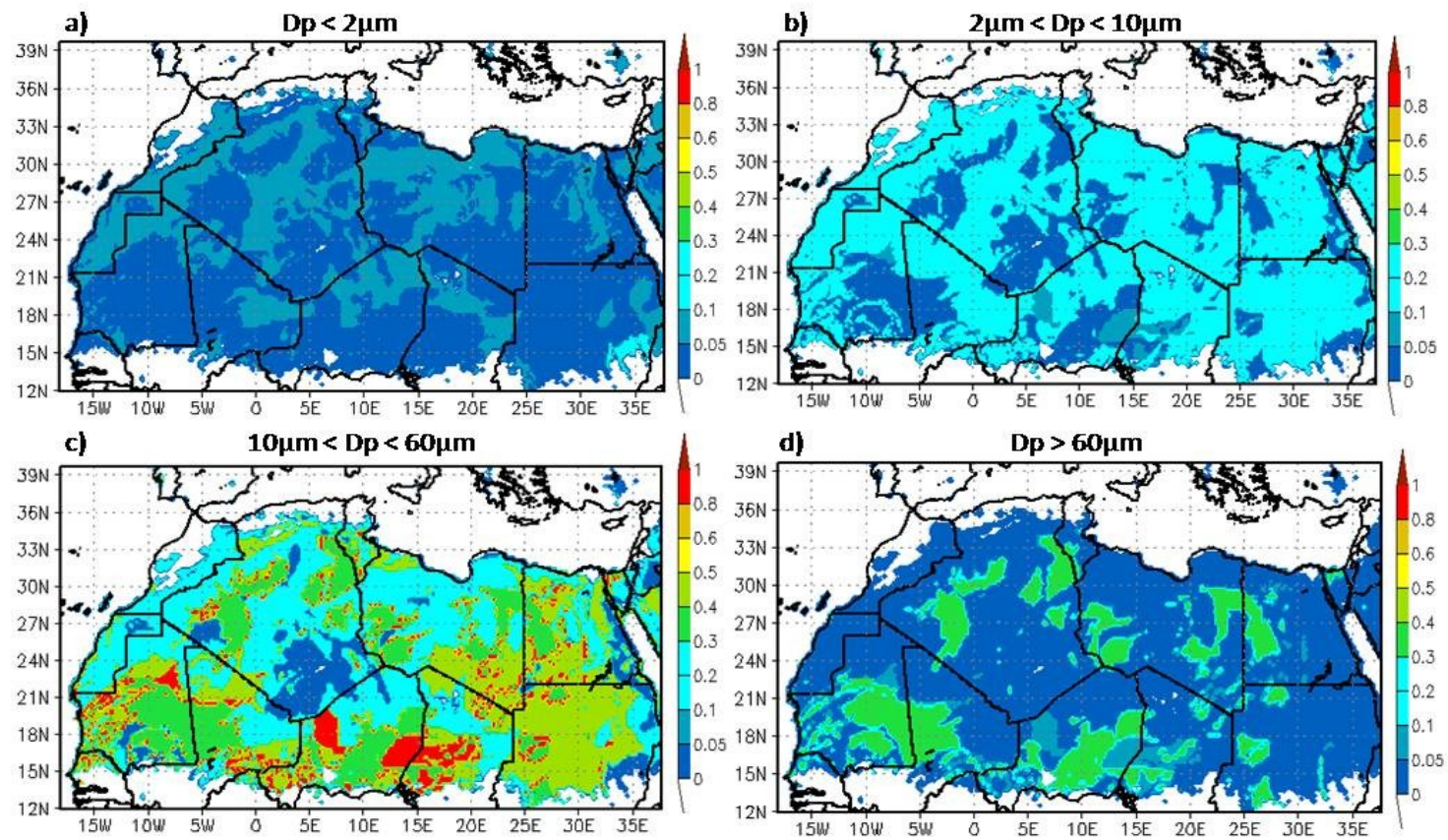

Fig. 4. The average relative surface area for each population of soil particles with diameter a) $D_{p}<2 \mu \mathrm{m}$, b) $2 \mu \mathrm{m}<D_{p}<10 \mu \mathrm{m}$, c) $10 \mu \mathrm{m}$ $<D_{p}<60 \mu \mathrm{m}$, and d) $D_{p}>60 \mu \mathrm{m}$.

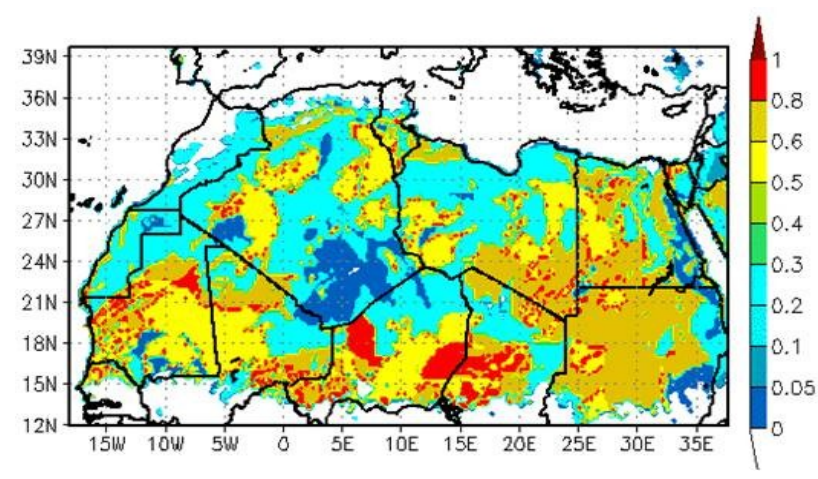

Fig. 5. Total average relative surface for the four populations of particles over northern Africa.

where $D_{\text {med }}$ is the median diameter of the coarsest mode for the twelve soil textures given in Table 2.

The roughness lengths used by the Interaction Soil Biosphere Atmosphere (ISBA) (Noilhan and Planton, 1989) scheme are derived from the ECOCLIMAP data bases. The value of $Z_{0}$ associated with bare soil (COVER004) is $13 \mathrm{~mm}$ (Masson et al., 2003). This value is used to quantify the momentum exchanges. However, this value is very large. It considerably influences the drag partition factor $\left(f_{d}\right)$ and gives a very high threshold friction velocity, which penalizes dust emissions. For that reason, DEAD adopts a uniform value $Z_{0}=100 \mu \mathrm{m}$ and $Z_{0 s}=33.3 \mu \mathrm{m}$. In our case, the smooth roughness length is derived from the relation of MaB95 and varies according to the soil texture, from $33.3 \mu \mathrm{m}$ for sand to $3 \mu \mathrm{m}$ for clay soils. The difference between $Z_{0 s}$ derived by MaB95 and $Z_{0}$ used in DEAD is significant. This gives high $f_{d}$ factor. To keep the same value for $f_{d}$ in the original and new versions of DEAD, a roughness length $Z_{0}=30 \mu \mathrm{m}$ was chosen for the revised version of DEAD, which is appropriate for the $\mathrm{Z}_{0 s}$ used.

Soil moisture generates a capillary force which is allowed to suppress dust deflation when the soil gravimetric water content $(w)$ exceeds a threshold soil moisture $\left(w^{\prime}\right)$. This threshold is defined in the revised DEAD scheme by the following relationship:

$w^{\prime}=b\left(0.17 M_{\text {clay }}+0.0014 M_{\text {clay }}^{2}\right)$ and $0.053<w^{\prime}<0.15$.

It was established, empirically, that setting $b=3$ in Eq. (7) provided a better fit to $w$ predicted by the ISBA scheme and resulted in a reasonable value of the erosion threshold velocity compared with that obtained by Fécan et al. (1999).

The factor accounting for the effect of soil moisture content on the threshold friction velocity $f_{w}$ was calculated using the following relationship (Fécan et al., 1999):

$f_{w}=\left\{\begin{array}{l}1 \quad \text { for } w \leq w^{\prime} \\ \sqrt{1+1.21\left[w-w^{\prime}\right]^{0.68}} \text { for } w>w^{\prime}\end{array}\right.$

$w$ and $w^{\prime}$ having units of $\mathrm{kg} / \mathrm{kg}$. 
Table 3. Log-normal parameters of the AMMA size distribution used in DEAD coupled with SURFEX.

\begin{tabular}{llll}
\hline Dust mode & Mode 1 & Mode 2 & Mode 3 \\
\hline Number fraction $(\%)$ & 97.52 & 1.95 & 0.52 \\
Mass fraction $(\%)$ & 0.08 & 0.92 & 99 \\
Geometric standard deviation & 1.75 & 1.76 & 1.70 \\
Number median diameter $(\mu \mathrm{m})$ & 0.078 & 0.64 & 5.0 \\
Mass median diameter $(\mu \mathrm{m})$ & 0.20 & 1.67 & 11.6 \\
\hline
\end{tabular}

The Owen effect was calculated using the following relationship (Zender et al., 2003):

$u_{* s}=u_{*}+0.003\left(U_{10}-U_{10, t}\right)^{2}$

where $u_{* s}$ is the friction velocity corrected for the Owen effect. $U_{10}$ and $U_{10, t}$ are the wind speed and the threshold wind speed, respectively at $10 \mathrm{~m}$.

The total horizontal saltating mass flux $G$ was calculated following MaB95:

$G=a . E . c \cdot \frac{\rho}{g} \cdot u_{*}^{3}\left(1+\frac{u_{* t}}{u_{*}}\right)\left(1-\frac{u_{* t}^{2}}{u_{*}^{2}}\right) \int_{D_{\mathrm{bin}}} d S_{\mathrm{rel}}\left(D_{\mathrm{bin}}\right) d D_{\mathrm{bin}}$

where $E$ is the fraction of the erodible surface represented by the COVER004, $a$ is the global mass flux tuning factor determined a posteriori through the model experiments, $c=2.61$, $g$ is the gravitational constant, $\rho$ is the atmospheric density and $d S_{\text {rel }}\left(D_{\text {bin }}\right)$ is the average relative surface area for each of the four populations shown in Fig. 4.

In the original DEAD version, the horizontal saltating mass flux $G$ is converted to a vertical dust mass flux $F$ with a sandblasting mass efficiency $\alpha$ which is parameterized following MaB95. This efficiency depends on the clay fraction in the parent soil and is restricted to $M_{\text {clay }}<20 \%$. At the local scale, this parameterization yields reasonable results (Marticorena et al., 1997) but, at the global scale, it proves to be overly sensitive to $M_{\text {clay }}$. For this reason, Zender et al. (2003) assign a constant value to the clay fraction $\left(M_{\text {clay }}=20 \%\right)$. However, this assumption provides a uniform value of $\alpha$ over all dust source emissions and makes the spatial variation of this efficiency less representative. In order to avoid this flaw in the revised DEAD, the Shao et al. (1996) sandblasting efficiency relationship is adopted:

$\alpha=\frac{F}{G}=\frac{2}{3} \times \frac{\rho_{p}}{\rho} \times \frac{\beta \gamma g}{\left[u_{* t}\left(D_{d}\right)\right]^{2}}$

$\gamma=2.5$

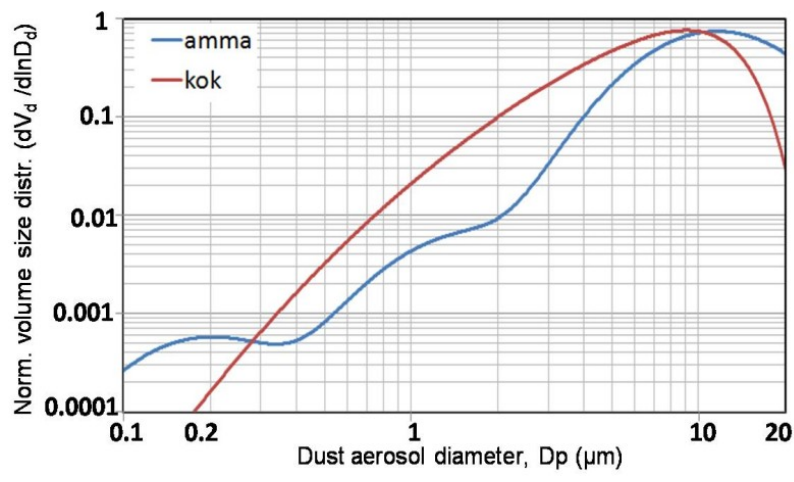

Fig. 6. Normalized volume size distribution of emitted dust aerosol given by AMMA distribution (blue line) and Kok theory (red line).

and

$\beta=\left[0.125 \times 10^{-4} \ln \left(D_{s}\right)+0.328 \times 10^{-4}\right] \exp \left(-140.7 . D_{d}+0.37\right)$

where $D_{d}$ and $D_{s}$ are in $\mathrm{mm}$ and $\beta>0$.

$D_{s}$ is the average diameter of the dust particles in saltation ( $\sim 75 \mu \mathrm{m})$, and $D_{d}$ is the average diameter of the suspended dust particles $(\sim 6.7 \mu \mathrm{m})$.

\subsection{Size distribution of transportable dust particles}

In the original DEAD, the emitted dust flux distribution is parameterized according to Alfaro and Gomes' (2001) sandblasting theory (Grini and Zender, 2004). This theory allows emitted dust fluxes to be distributed into three modes, according to the friction velocity. The measurements taken during the AMMA Special Observation Period (SOP) of June 2006 (Crumeyrolle et al., 2011) confirm the existence of a mode of particles centered around $0.64 \mu \mathrm{m}$ but indicate that almost $99 \%$ of the number concentration is included in other particle modes finer than that centered around $0.64 \mu \mathrm{m}$. Therefore, based on the AMMA measurement and the Alfaro and Gomes (2001) sandblasting theory, Crumeyrolle et al. (2011) proposed a new tri-modal size distribution (AMMA) for the emitted dust fluxes in the DEAD, coupled to SURFEX. The parameters related to the AMMA distribution are given in Table 3 .

On the basis of many published measurements of sizedistributed dust flux, Kok (2011) argued that the size 

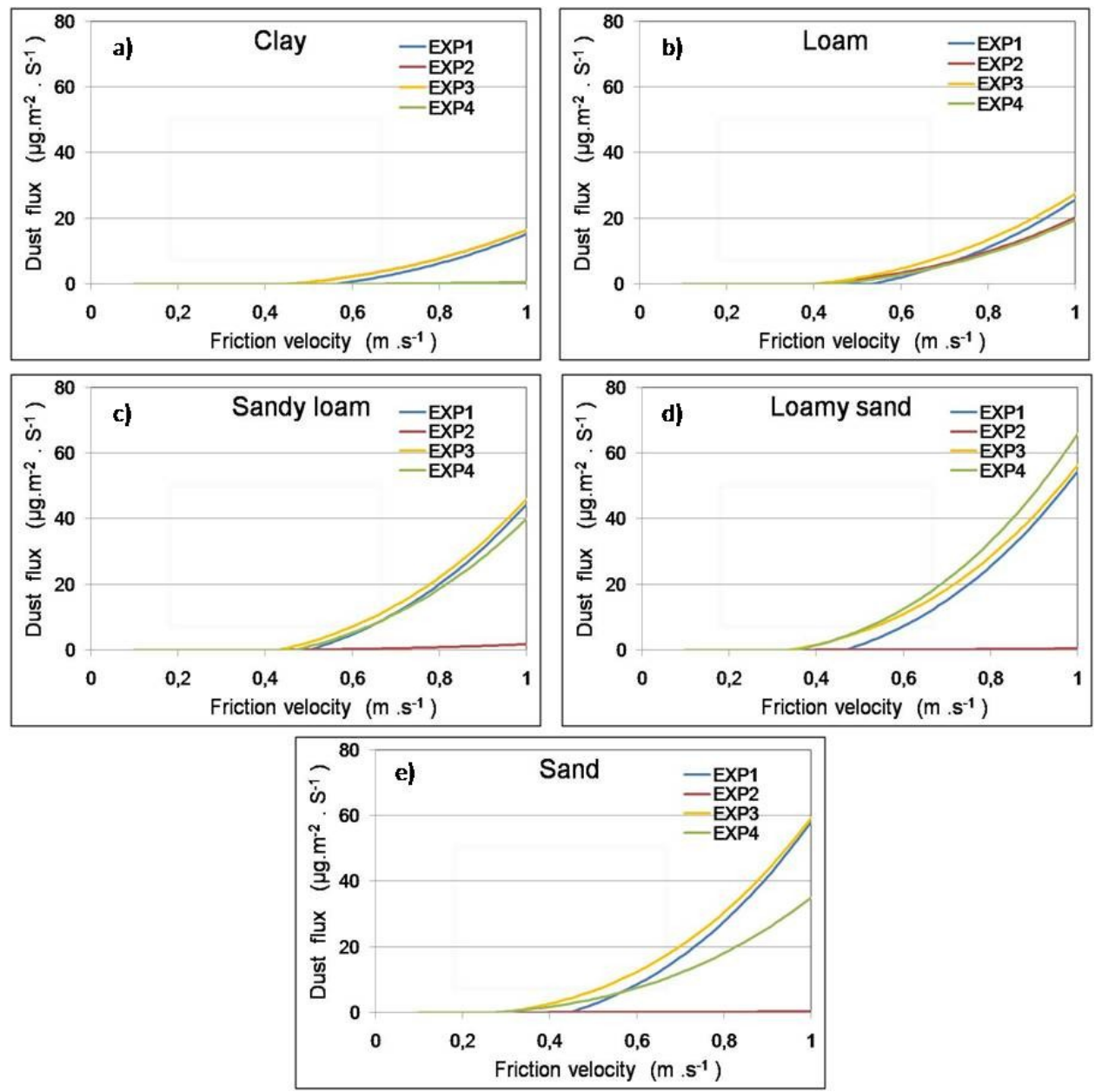

Fig. 7. Evolution of the surface dust fluxes (in $\mu \mathrm{g} \mathrm{m}^{-2} \mathrm{~s}^{-1}$ ) depending on the friction velocity ( $\mathrm{m} \mathrm{s}^{-1}$ ) over: (a) Clay soil (b) loam soil, (c) sandy loam soil, (d) loamy sand soil, and (e) sand soil.

distribution of mineral dust emissions was independent of the wind speed and found little sensitivity of the emitted dust size distribution to soil textures. Furthermore, Kok (2011) proposed a theoretical emitted dust distribution depending on one median diameter $\left(D_{s}=3.4 \mu \mathrm{m}\right)$ and geometric standard deviation $\left(\sigma_{s}=3.0\right)$. The difference between Kok's distribution and the AMMA distribution (Fig. 6) is very noticeable and it is clear that Kok's distribution is coarser and neglects the fine mode, which is confirmed by the AMMA observations. This is related to the fact that this theory is based on measurements taken near the surface. However, the AMMA distribution is based on aircraft measurements taken at an altitude of around $700 \mathrm{~m}$ above mean sea level between $\mathrm{Ni}$ amey (Niger) and Cotonou (Benin). These regions are far from dust sources and fine dust particles are more dominant there because they have a small sedimentation velocity and a long atmospheric residence time. This fine mode is very important and the dust particles act as ice nuclei. So, the AMMA distribution is adopted for the revised DEAD version in order to represent the transportable dust particles well in the west of Africa.

Dry deposition and sedimentation of dust aerosols are driven by Brownian diffusivity and by gravitational velocity (see Tulet et al., 2005 and Grini et al., 2006 for details).

\section{Sensitivity study: comparison between the revised DEAD version and the old scheme}

In this section, a sensitivity study is conducted in order to show the performance and importance of the modifications introduced in the DEAD scheme. This part of the study contains two experiments: the first in 0-D and the second in 3-D, in which the situations of 7 March 2006 are simulated.

\subsection{0-D simulation configurations}

0-D simulations of the variation of surface dust fluxes depending on the friction velocity over a specific point were 
conducted with the four different configurations of surface fluxes (EXP1, EXP2, EXP3 and EXP4) defined in Table 4. The main objective of using the four configurations was to quantify the different processes over soil types, in particular the vertical dust flux and the threshold friction velocity. Figure 7 shows the variation of the vertical dust fluxes depending on the friction velocity for the four configurations tested over clay soil (Fig. 7a), loamy soil (Fig. 7b), sandy loam soil (Fig. 7c), loamy sand soil (Fig. 7d), and sand soil (Fig. 7e). The goal of the EXP1 configuration was to show the influence of the Fécan (1999) formulation on the threshold friction velocity and to highlight the adapted Fécan formulation (Eq. 7) used in the revised DEAD scheme. The EXP2 configuration showed the consequences of the MaB95 formulation in the calculation of the sandblasting efficiency $\alpha$ when the variation of clay fraction in the soil from 0 to $20 \%$ was taken into account. The EXP3 configuration was the current version of DEAD used in SURFEX. Finally, the EXP4 configuration was the revised version of DEAD proposed in this paper. For all configurations, the same forcing soil wetness field given by the ISBA scheme was used.

\subsubsection{Clay soil}

Clay soil occupies a very limited area of the North African Sahara desert, particularly at latitude $33^{\circ}$ North, between the Algerian and Tunisian border, and in extreme southeastern Sudan, between $12^{\circ}$ and $15^{\circ}$ latitude north. This soil contains over $40 \%$ clay. This substance acts as cement in the soil and fortifies the cohesion force. Over this type of soil, the threshold friction velocity obtained by the EXP2, EXP3 and EXP4 configurations was $0.5 \mathrm{~ms}^{-1}$, but that obtained by EXP1 was higher: $0.6 \mathrm{~ms}^{-1}$ (Table 5). Concerning surface fluxes (Fig. 7a), EXP1, EXP2, and EXP3 showed the same sandblasting efficiency $\alpha$ and convergence in the curves, depending on the friction velocity. In contrast, EXP4 provided a very weak surface flux which did not exceed 1 $\mu \mathrm{g} \mathrm{m}^{-2} \cdot \mathrm{s}^{-1}$. This underestimation was caused by the very low value of the total average relative area of the four populations (Fig. 5), which did not exceed 0.05 over this soil. In conclusion, EXP1, EXP2, and EXP3 showed that the potential dust sources of clay soil were relatively weak, while EXP4 excluded it from the potential dust sources. It is true that the sandblasting efficiency is dependent on fine particles contained in the soil but is also controlled by large particles. Indeed, it is these particles that allow the release of fine particles when they are activated by saltation. However, clay soil has very few large particles and does not favour the saltation motion. It is thus reasonable that a low surface dust flux should be obtained over this soil.

\subsubsection{Loamy soils}

Loamy soil is the dominant type of soil in the Sahara desert. Over this soil, EXP2, EXP3, and EXP4 started the dust emis- sion at a friction velocity around $0.45 \mathrm{~ms}^{-1}$, but the EXP1 started at a friction velocity around $0.55 \mathrm{~ms}^{-1}$ (Table 5). Concerning the surface fluxes (Fig. 7b), for a wind friction velocity of less than $0.8 \mathrm{~ms}^{-1}$, the evolution was nearly the same for the four representations. Beyond this velocity, the surface dust fluxes obtained with EXP1 and EXP3 were greater than those calculated with EXP2 and EXP4. In conclusion, the four representations found that loamy soil was a relatively moderate dust emission source.

\subsubsection{Sandy loam soils}

Sandy loam soil occupies the major part of northern Sudan and southern Egypt and Libya, a local part of the Bodélé depression, southern Niger and northern Mali and Mauritania. For these soils, the threshold friction velocity obtained by EXP2, EXP3, and EXP4 was around $0.42 \mathrm{~ms}^{-1}$, but EXP1 started dust emission at a friction velocity around $0.5 \mathrm{~ms}^{-1}$ (Table 5). Concerning surface fluxes (Fig. 7c), EXP1, EXP3 and EXP4 provided similar surface dust fluxes. In contrast, EXP2 provided very weak surface dust fluxes. In conclusion, EXP1, EXP3, and EXP4 showed that sandy loam soil was a moderate dust emission source but EXP2 excluded it from potential dust sources. It can be seen that the sandblasting efficiency was calculated in EXP2 by MaB95 for a varied clay fraction. For this type of soil, the percentage of clay is around $12 \%$, so the sandblasting efficiency ratio between this type of soil and that of soil with $20 \%$ of clay is around 10 , explaining the low value of this efficiency when the variation of the amount of clay in the ground was taken into account.

\subsubsection{Loamy sand soils}

These soils occupy a large part of the Bodélé depression, a part of the Algerian and Nigerian border, and a limited area in the Mauritanian and Algerian desert. Over loamy sand soil, EXP3 and EXP4 started dust erosion at around $0.37 \mathrm{~ms}^{-1}$, whereas EXP1 started mobilization at around $0.48 \mathrm{~ms}^{-1}(\mathrm{Ta}-$ ble 5). As for surface fluxes (Fig. 7d), EXP1 and EXP3 showed a large evolution of dust surface fluxes, whereas EXP4 presented a very large evolution of dust surface fluxes. On the other hand, as before with sandy loam soils, EXP2 did not create significant dust surface fluxes. However, these soils are considered as the largest dust emission source in north Africa. Therefore, they are very well represented by the EXP4 configuration.

\subsubsection{Sand soils}

These soils cover a large part of Mauritania and Niger, the eastern and western Great Erg of Algeria and a localized part of Egypt, Libya, and Sudan. Over sand soil, EXP3 and EXP4 started the dust mobilization at around $0.28 \mathrm{~ms}^{-1}$, but EXP1 began mobilization at a friction velocity around $0.43 \mathrm{~ms}^{-1}$ (Table 5). As for surface fluxes (Fig. 7e), EXP1 and EXP3 provided very strong dust flux values and indicated that this 
Table 4. Definition of the four configurations tested for five types of soils.

\begin{tabular}{|c|c|c|c|c|}
\hline Compared elements & EXP1 & EXP2 & EXP3 & EXP4 \\
\hline $\begin{array}{l}\text { Geographic size } \\
\text { distribution }\end{array}$ & $\begin{array}{l}\text { Uniform } \\
\text { texture }\end{array}$ & $\begin{array}{l}\text { Uniform } \\
\text { texture }\end{array}$ & $\begin{array}{l}\text { Uniform } \\
\text { texture }\end{array}$ & $\begin{array}{l}\text { USDA } \\
\text { textures }\end{array}$ \\
\hline Moisture effect & Fécan (1999) & $\begin{array}{l}\text { Fécan (1999) } \\
\text { with } w^{\prime} \text { given } \\
\text { by Eq. (7) }\end{array}$ & $\begin{array}{l}\text { Fécan (1999) } \\
\text { with } w^{\prime} \text { given } \\
\text { by Eq. (7) }\end{array}$ & $\begin{array}{l}\text { Fécan (1999) } \\
\text { with } w^{\prime} \text { given } \\
\text { by Eq. ( } 7)\end{array}$ \\
\hline Drag partition effect & $\begin{array}{l}\text { MaB95 with } \\
\mathrm{Z}_{0}=100 \mu \mathrm{m} \\
\mathrm{Z}_{0 s}=33.3 \mu \mathrm{m}\end{array}$ & $\begin{array}{l}\text { MaB95 with } \\
\mathrm{Z}_{0}=100 \mu \mathrm{m} \\
\mathrm{Z}_{0 s}=33.3 \mu \mathrm{m}\end{array}$ & $\begin{array}{l}\text { MaB95 with } \\
\mathrm{Z}_{0}=100 \mu \mathrm{m} \\
\mathrm{Z}_{0 s}=33.3 \mu \mathrm{m}\end{array}$ & $\begin{array}{l}\text { MaB95 with } \\
\mathrm{Z}_{0}=30 \mu \mathrm{m} \\
\mathrm{Z}_{0 s}=\mathrm{D}_{\text {med }} / 30 \mu \mathrm{m}\end{array}$ \\
\hline Saltation fluxes & White (1979) & White (1979) & White (1979) & MaB95 \\
\hline $\begin{array}{l}\text { Sandblasting efficiency } \\
\alpha=F / G\end{array}$ & MaB95 with $\mathrm{M}_{\text {clay }}=20 \%$ & $\begin{array}{l}\text { MaB95 with } \mathrm{M}_{\text {clay }}=20 \% \\
0<\mathrm{M}_{\text {clay }}<20 \%\end{array}$ & MaB95 with $\mathrm{M}_{\text {clay }}=20 \%$ & Shao et al. (1996) \\
\hline Dust source intensity & $\mathrm{M}_{\text {sand }}$ & $\mathrm{M}_{\text {sand }}$ & $\mathrm{M}_{\text {sand }}$ & $\begin{array}{l}\text { Relative surface } d S_{\text {rel }} \\
\left(D_{\text {bin }}\right) \text { for each } \\
\text { of the four populations }\end{array}$ \\
\hline
\end{tabular}
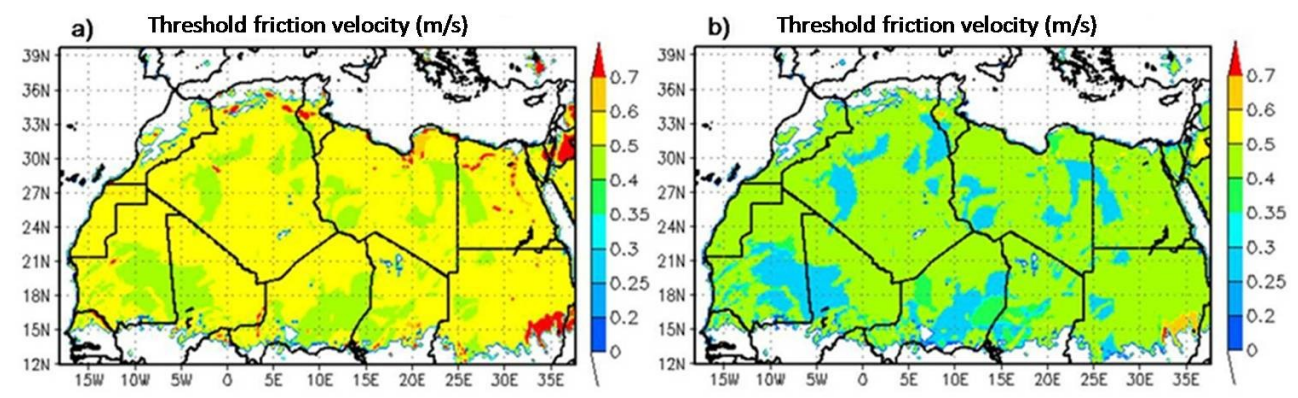

Fig. 8. Threshold friction velocity in $\mathrm{ms}^{-1}$ calculated by MaB95, incorporating the soil moisture effect in accordance with: (a) Fécan at al. (1999) and (b) adapted Fécan formulation (Eq. 7).

Table 5. Threshold friction velocity $\left(u_{* t}\right)$ in $\mathrm{m} . \mathrm{s}^{-1}$ obtained with EXP1, EXP2, EXP3, and EXP4 configurations over clay soil, loamy soil, sandy loam soil, loamy sand soil, and sand soil.

\begin{tabular}{lllll}
\hline Soil type & EXP1 & EXP2 & EXP3 & EXP4 \\
\hline Clay soil & 0.6 & 0.5 & 0.5 & 0.5 \\
Loamy soil & 0.55 & 0.45 & 0.45 & 0.45 \\
Sandy loam soil & 0.5 & 0.42 & 0.42 & 0.42 \\
Loamy sand soil & 0.48 & 0.37 & 0.37 & 0.37 \\
Sand soil & 0.43 & 0.28 & 0.28 & 0.28 \\
\hline
\end{tabular}

soil is the most important dust emission source. However, these soils have few fine particles and their aggregate is very coarse. In theory, these soils should provide low dust fluxes, in contrast with EXP1 and EXP3. On the other hand, EXP4 provided reasonable fluxes and classified this soil after loamy sand and sandy loam in terms of source intensity.

\subsubsection{Preliminary conclusions}

Through this experiment, we can conclude that the Fécan (1999) formulation provides very low threshold soil moisture. So this threshold is often exceeded by soil moisture calculated by the ISBA scheme. Consequently, a correction of the threshold friction velocity is applied. This explains the high value of the threshold friction velocity obtained by EXP1 configuration over all soils (Fig. 8a).

The sandblasting efficiency (Fig. 9a) calculated by the MaB95 formulation for a variable fraction of clay provides very low fluxes over sandy loam, loamy sand, and sandy soils which is clarified in EXP2. These soil types cover the northern part of Sudan, the southern part of Egypt, the Bodélé depression, a large part of Mauritania, Mali and Niger, and finally, the eastern and western Great Erg of Algeria. These zones are classified as potential dust source areas in some research (Laurent et al., 2008) but they are ignored in the EXP2 configuration. 

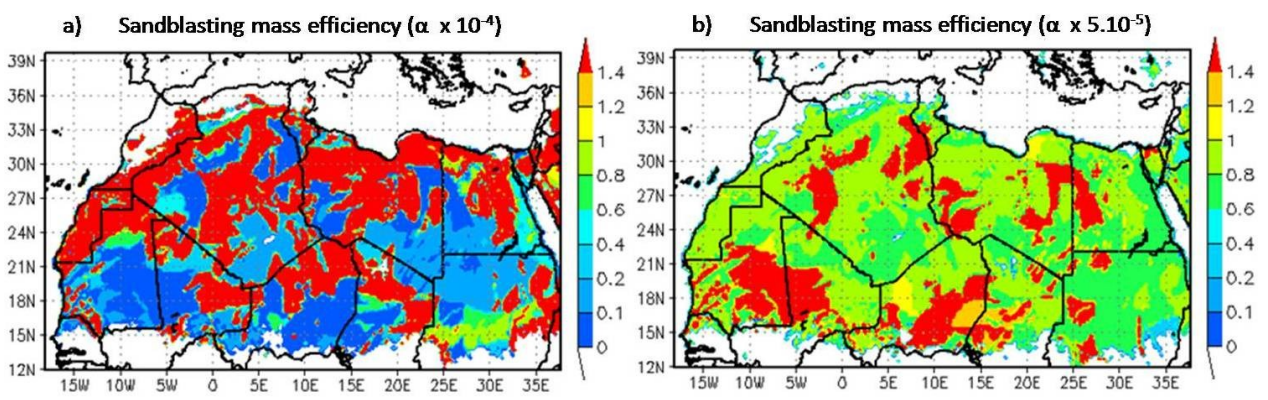

Fig. 9. Sandblasting mass efficiency $(\alpha)$ in $\mathrm{m}^{-1}$ calculated by: (a) MaB95 with $0 \%<$ clay<20\% and (b) Shao et al. (1996).
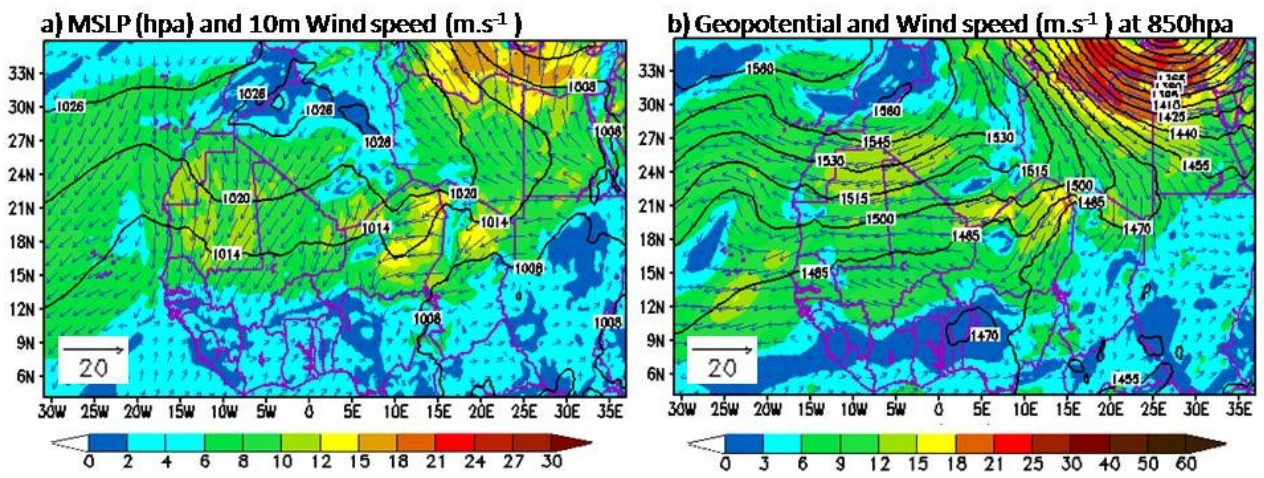

Fig. 10. Mean sea level pressure (hPa) and wind speed at $10 \mathrm{~m}$ (a) and geopotential (in metres) and wind speed at $850 \mathrm{hPa}(\mathbf{b})$, on 8 March 2006 at 12:00 UTC.

EXP3 and EXP4 give a reasonable threshold friction velocity (Fig. 9b). The minimum value was obtained for sandy soil $\left(0.28 \mathrm{~ms}^{-1}\right)$. This value is in agreement with that obtained by Marticorena et al. (1997) over this soil ( 7 to $8 \mathrm{~ms}^{-1}$ at $10 \mathrm{~m}$ ). This fact explains the efficiency of the adapted Fécan (1999) formulation presented in Eq. (7). For surface fluxes, EXP3 presents uniform sandblasting efficiency for all soil types. Therefore, the only parameter which differentiated the potential dust sources was the sand fraction (Fig. 2b). This configuration classified sandy soil first in terms of source intensity, loamy sand soil second, and sandy loam soil as third. However, it was noted that sandy soil was made up of coarse sand and had few fine particles. The value of sandblasting efficiency, $\alpha$, assigned by Marticorena et al. (1997) for similar types of soil is very low $\left(1.0 \times 10^{-7}\right.$ $\mathrm{cm}^{-1}$ ). On the other hand, EXP4 represents the potential dust source by the total average relative surface area (Fig. 5) and classifies loamy sand and sandy loam as more important dust sources. These soils contain a high percentage of large particles supporting the movement by saltation and, at the same time, a sufficient percentage of fine particles to ensure vertical release. Thus they are very well represented by the EXP4 configuration.

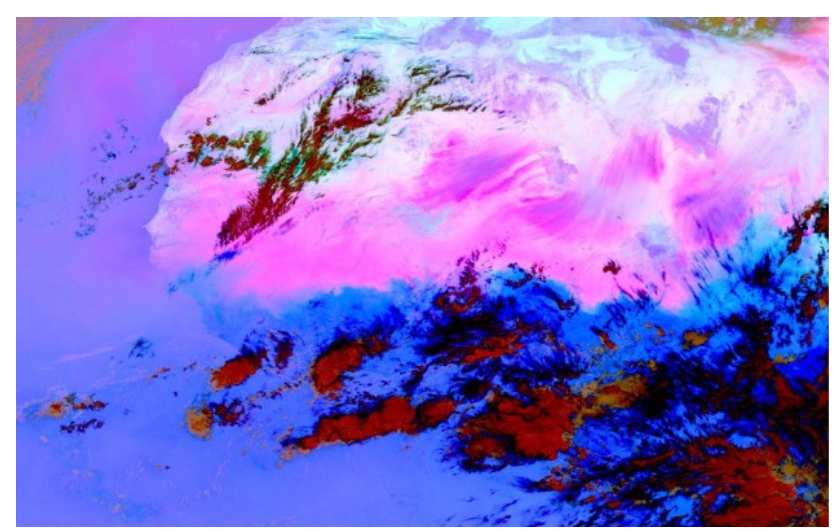

Fig. 11. MSG-SEVIRI satellite image over West Africa for 8 March 2006 at 12:00 UTC. Pink color represents dust, black: cirrus, red: high-level cloud, brown: mid-level cloud, and white: desert surface.

\subsection{3-D Simulation: 7-13 March case study}

The 7-13 March dust storm was a synoptic event affecting most regions of northern Africa. The wind speeds during this event exceeded the erosion thresholds in most of the Sahara. Thus it was a favourable situation for identifying and 

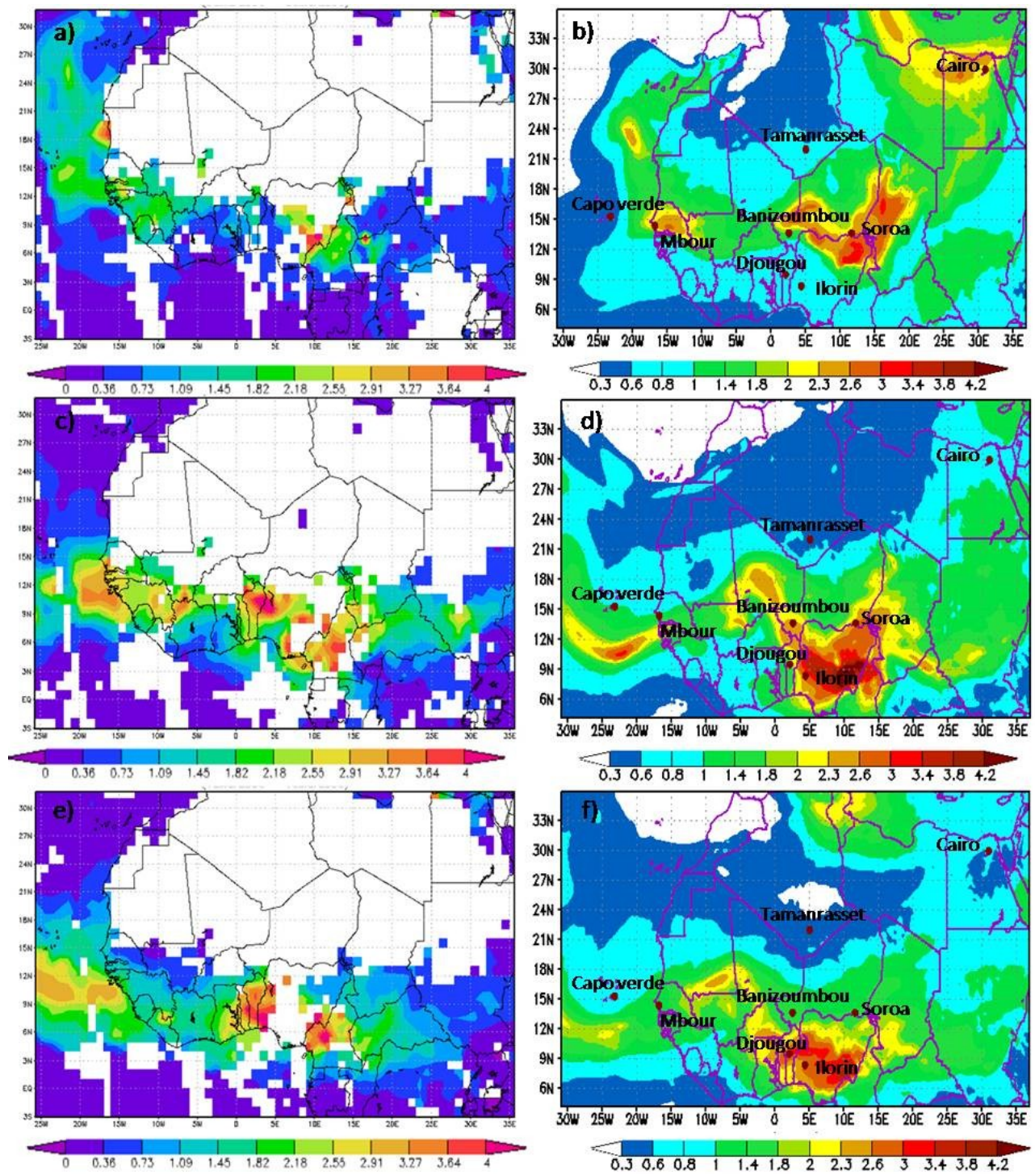

Fig. 12. Daily mean AOD (at $550 \mathrm{~nm}$ ) from MODIS/AQUA satellite images (a, c and e) and simulated by ALADIN (b, d and f) for 8 March (top), 10 (middle) and 12 (bottom), 2006.

locating the essential dust emission areas over north Africa. This event has been well described by Slingo et al. (2006) and Marticorena et al. (2010) and further analysed by Tulet et al. (2008), Mallet et al. (2009), and Kocha et al. (2011). As described in Slingo et al. (2006), it was initiated by a cold front in the lee of the Atlas mountains, which progressed southward and westward, producing dust emission along its path. In this section, we simulate this event by using the previous configurations defined in Table 4 in order to illustrate the behaviour of each representation in three dimensions. EXP1 and EXP2 were fused into one configuration, THR, known as the theoretical version, where we used the Fécan (1999) formulation to estimate the soil moisture effect and the MaB95 formulation to calculate the sandblasting efficiency $\alpha$. EXP3 and EXP4 were as represented in Table 4. The results were combined with available data from AMMA.

\subsubsection{Model configuration and dust transport}

The spectral hydrostatic atmospheric model ALADIN was used in this study. This model was developed with international cooperation led by Météo France, and is used operationally for weather prediction. It is a fully threedimensional, baroclinic system of primitive equations using a two-time-level semi-Lagrangian semi-implicit numerical integration scheme and a digital filter initialization (Huth et al., 2003). The physical parameterization package comprises: gravity wave drag parameterization, semi-Lagrangian 

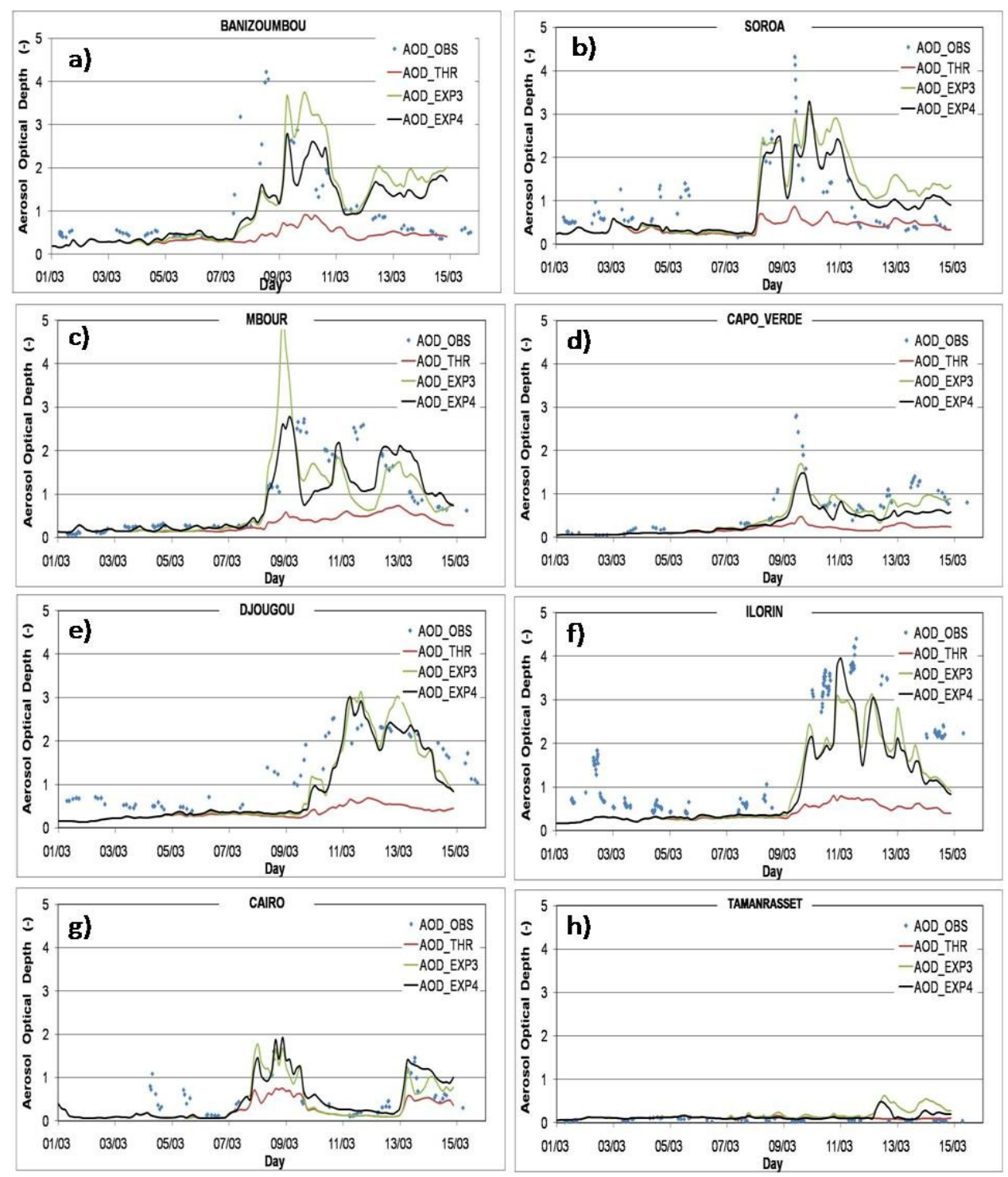

Fig. 13. Evolution of the AOD (at $550 \mathrm{~nm}$ ) simulated by ALADIN with three dust emission schemes: THR (red line), EXP3 (green line) and EXP4 (black line), between 1 and 15 March 2006, over (a) Banizoumbou, (b) Soroa, (c) Mbour, (d) Capo Verde, (e) Djougou, (f) Ilorin, (g) Cairo, and (h) Tamanrasset, compared with AERONET photometer observations AOD_440 (level 2).

horizontal diffusion (SLDH) computed in spectral space, vertical diffusion and planetary boundary layer parameterization, sub-grid scale deep convection and convective precipitations, the RRTM scheme (Rapid Radiative Transfer Model) for longwave radiation (Mlawer et al., 1997), and Fouquart Morcrette code for shortwave radiation with six spectral bands. The simple large-scale cloudiness and precipitation scheme was developed by Lopez (2002). For a complete scientific description, readers are referred to Bubnová et al. (1995), Radnóti (1995), Horányi et al. (1996), Geleyn (1998), and Váòa (1998).
Surface processes are calculated by SURFEX and include: the ISBA scheme (Noilhan and Planton, 1989), sea (ECUME fluxes), Town Energy Balance (TEB) (Masson, 2000), and lakes.

Dust aerosols are transported using the log-normal aerosol dynamic model ORILAM (Tulet et al., 2005).

The vertical diffusion of dust aerosols is calculated in ALADIN, as are temperature and moisture diffusion (Gibelin, 2004). Thus, the exchange coefficient used for temperature and moisture is also applied for dust aerosols.

The wet removal of dust aerosols is calculated using the SCAVenging submodel (Tost et al., 2006) developed for the 

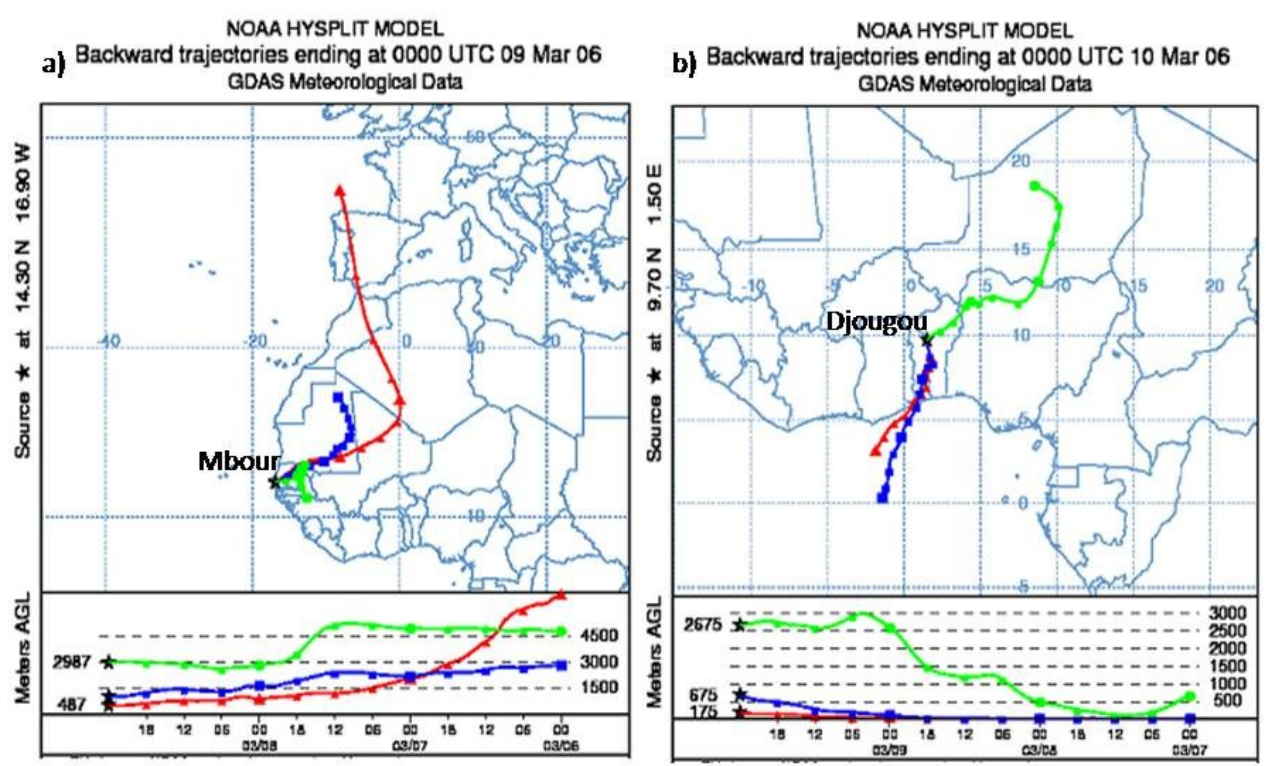

Fig. 14. NOAA Hysplit Model, backward trajectories at the $500 \mathrm{~m}$ level (red line), 1000 mlevel (blue line) and $3000 \mathrm{~m}$ level (green line) ending at: (a) 00:00 UTC, 9 March 2006, over Mbour and (b) 00:00 UTC, 10 March 2006, over Djougou.

Mesoscale Non-Hydrostatic atmospheric model (MesoNH). For details of this formulation, refer to Tulet et al. (2010), Tost et al. (2006), and Berthet et al. (2010).

The horizontal resolution of the ALADIN model version used in this study is $24 \mathrm{~km}$ centered over north Africa with 60 vertical levels; from the surface to $67 \mathrm{~km}$. ALADIN is forced by the atmospheric global model ARPEGE, which provides initial and lateral boundary conditions. In order to minimise spin up and establish reliable dust concentration conditions, the simulation was started from 1 March 2006 with a $48 \mathrm{~h}$ forecast with simulated dust concentration from a previous forecast used to initialize the dust concentration for the next model run. The time interval between the previous and next model runs was $48 \mathrm{~h}$.

\subsubsection{Synoptic situation}

The 2006, 7-13 March west African dust event was generated by a strong pressure gradient over western Africa between 7 and 9 March (Fig. 10). The $850 \mathrm{hPa}$ geopotential field from 8 March at 12:00 UTC, forecasted by ALADIN (Fig. 10b), shows high pressure over Mauritania and low pressure over Libya. This strong geopotential gradient generated an intense Harmattan surface flux over northern Niger and Chad $\left(15 \mathrm{~ms}^{-1}\right)$, northern Mali $\left(12 \mathrm{~ms}^{-1}\right)$, and Mauritania $\left(12 \mathrm{~ms}^{-1}\right)$ (Fig. 10a). During the 7-13 March period, these strong surface winds led to an intense dust storm, which could be readily observed on the MSG-SEVIRI satellite images (Schmetz et al., 2006; Slingo et al., 2006) on 8 March at 12:00 UTC (Fig. 11). A high dust plume was observed, spreading from the desert regions of Mali, Niger, and Chad to the south-western part of the domain. The evolution of the AOD (at $550 \mathrm{~nm}$ ) was observed by the AQUA-MODIS satellite (Fig. 12a, c and e). These data were obtained from the MODIS online visualization and Analysis System (MOVAS) tool, developed at NASA (http: //disc.sci.gsfc.nasa.gov/giovanni\#maincontent). On 8 March (Fig. 12a), dust plumes did not reach the Gulf of Guinea and were still located north of Benin and in the center of Nigeria. On 10 March, it is interesting to note that the AQUAMODIS satellite also retrieved three AOD maxima exceeding 3 in the same location around Nigeria (Fig. 12c). On 12 March, AQUA-MODIS observed large AOD over Benin, Nigeria, and Cameroon exceeding 3 in the coastal regions (Fig. 12e).

The evolution of the AOD (at $550 \mathrm{~nm}$ ) for Sahelian dust simulated by ALADIN (Fig. 12b, d and f) showed a strong band of large AOD appearing from Chad to Senegal on 8 March. Various AOD were simulated in Chad (3), the southern part of Niger, northern Nigeria (3.4), and Senegal (3) (Fig. 12b) in agreement with AQUA-MODIS observations. On the other hand, a delay in the initiation of the dust event at Capo Verde, Djougou, and Ilorin is found. On 10 March (Fig. 12d), the dust plume spread to the south, reaching the Gulf of Guinea. In particular, three maxima of AOD were simulated: the first maximum, around 3, was simulated above Nigeria (from Benin to southern Chad and Cameroon), the second and the third maxima were around 2.6 and were simulated, respectively, over Mali and western Senegal toward the Atlantic Ocean. On 12 March, the intense dust plume continued its extension to the south over the Gulf of Guinea and the Atlantic Ocean but decreased in intensity over the whole domain (Fig. 12f). It is interesting to note that 
the coupled system ALADIN-SURFEX predicted the dominant features of this event well, especially the pronounced dust emission over much of the Sahara, the spatial and time evolution of the dust storm and, finally, the southern transport towards the Gulf of Guinea.

\subsubsection{Temporal evolution of AOD between 1 and 15 March 2006}

The simulated AOD between 1 and 15 March 2006 were compared with in situ AERONET photometer measurements taken at: Banizoumbou (Niger) and DMN Meine Soroa (Niger), to check the dust emission source, Mbour (Senegal) and Capo Verde, to check the western transport towards the Atlantic Ocean, Djougou (Benin) and Ilorin (Nigeria), to check the southern transport towards the Gulf of Guinea, and finally, Cairo (Egypt) and Tamanrasset (Algeria) to provide supplementary data. The results are illustrated in Fig. 13, where the observed AODs are represented by blue dots, THR, EXP3, and EXP4 are represented by a red, a green, and a black line, respectively.

Banizoumbou and Soroa mark the southern border of dust source in north Africa, with a sandy loam soil type. During the dust storm event, these two regions were simultaneously fed by the local dust source and the Harmattan dust flux. Over these two stations, investigation of the AOD observations showed that the dust storm event started on 7 March and ended on 11 March (Fig. 13a and b). The maximum AOD was observed on 8 March, reaching 4.2 over Banizoumbou. That observed over Soroa was on 9 March and reached 4.3. After 11 March, AOD decreased and became less than 1. Concerning simulated AOD, EXP3, and EXP4 started dust ascension in agreement with the observations over Soroa but, over Banizoumbou, a difference in intensity was notable. On 9 and 10 March, the AOD simulated over Banizoumbou with EXP3 reached 3.5 but the observations did not exceed 2.8. EXP4 predicted AOD in agreement with observations on 9 March (2.8) but, on 10 March, the predicted value of AOD was slightly over the estimate (2.6). On the other hand, the AOD simulated by THR was largely underestimated and did not exceed 1 during the dust storm event.

Mbour and Capo Verde were affected by the dust aerosols transported toward western Africa and the Atlantic Ocean. Over these two stations, the maximum observed AOD was seen on 9 March and exceeded 2.5 (Fig. 13c and Fig. 13d). However, EXP3 predicted a peak of AOD exceeding 5 over Mbour on 9 March but that predicted by EXP4 at the same time was in agreement with the observations. To understand this anomaly and its origin, the trajectory of the air mass was reproduced with the NOAA Hysplit model at the $500 \mathrm{~m}$ level (red line), $1000 \mathrm{~m}$ level (blue line), and $3000 \mathrm{~m}$ level (green line) (Fig. 14a). This figure shows the trajectory of the air mass overflowing Mauritania and Mali. These regions are covered with sandy soil and considered by EXP3 as an im- portant dust emission source but as only a moderate source by EXP4. For THR, it is noted that simulated AOD was underestimated during the dust storm event.

Djougou and Ilorin were affected by the northern flux that transported dust aerosols toward the Gulf of Guinea. The recorded AOD shows that the dust plume reached Djougou on 8 March (Fig. 13e), where AOD was greater than 1, but Ilorin was affected on 10 March (Fig. 13f). The NOAA Hysplit model trajectory (Fig. 14b) shows that the trajectories of the air masses at the surface and at mean plume altitude, which arrived over Djougou on 10 March, came from the Atlantic Ocean and the Gulf of Guinea (red and blue lines) and were thus saturated by salt aerosols. However, these aerosols were weakly diffused and influenced the AOD less. On the other hand, at a higher altitude (green line), the trajectory came from the north-east, sweeping through the center of Niger, and northern Nigeria, which was already affected by the dust storm between 8 and 10 March. During this period, ALADIN simulated this transport with a delay and underestimated the AOD. Between 11 and 14 March, the observed AOD over Djougou exceeded 2 and then decreased after 14 March. These AOD were very well predicted by EXP3 and EXP4 except on 13 March, where EXP3 overestimated the AOD. Over Ilorin, strong AOD were observed during these days, with a maximum exceeding 4 on 11 March. These AOD were underestimated by the EXP3 representation as in the study by Tulet et al. (2008) but the EXP4 forecast reached 4 on 11 March.

Over Cairo (Fig. 13g), there were two episodes for the dust event. The first, was from 7 March to 9 March, during which the observed AOD attained a value of 1.7 on 8 March. The second episode was observed on 13 March. These episodes were very well simulated by the EXP3 and EXP4 representations, but they were not taken into account by the THR configuration. Over Tamanrasset (Fig. 13h), the simulated AODs were small and were in agreement with the observations.

To summarize, dust storm events were well simulated over Africa by EXP3 and EXP4. In terms of intensity, EXP4 reproduced the AOD values better than EXP3, especially over Mbour, Djougou, and Ilorin, but over Soroa, Cairo, and Tamanrasset they converged. In terms of extension and transport, both configurations showed a delay in the transport of dust aerosols for stations far from the dust sources, in particular Capo Verde for the western transport and Djougou for the southern transport. It is interesting to note that the three parameterizations missed the beginning of the dust event over Banizoumbou, and also that the AOD was poorly simulated by THR over all stations during the dust storm event.

\subsubsection{Temporal evolution of dust surface concentration between 1 and 15 March 2006}

The evolution of dust surface concentration over Banizoumbou and Mbour between 1 and 15 March simulated by ALADIN with the above three dust emission configurations 

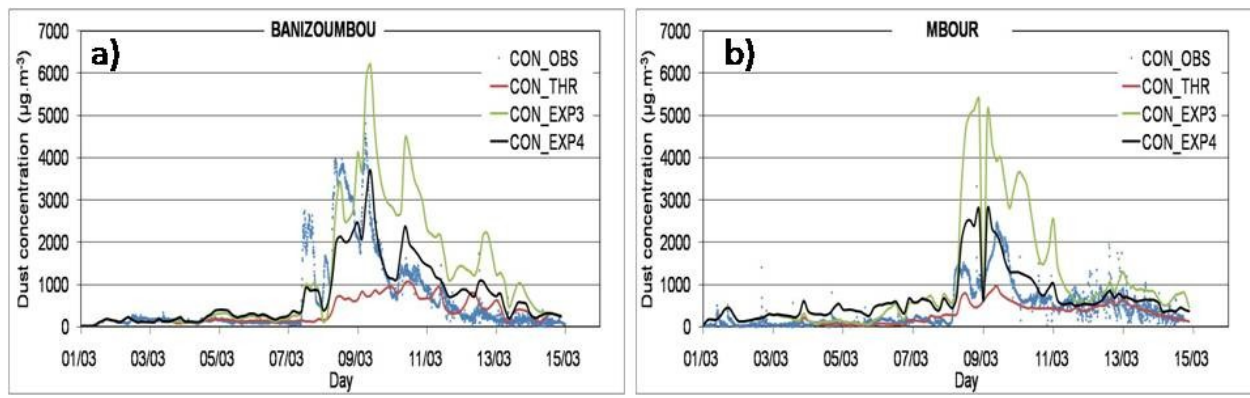

Fig. 15. Evolution of the dust surface concentration in $\left(\mu \mathrm{gm}^{-3}\right)$ simulated by ALADIN, with three dust emission configurations: THR (red line), EXP3 (green line) and EXP4 (black line), between 1 and 15 March 2006, over (a) Banizoumbou and (b) Mbour, compared with the observations.
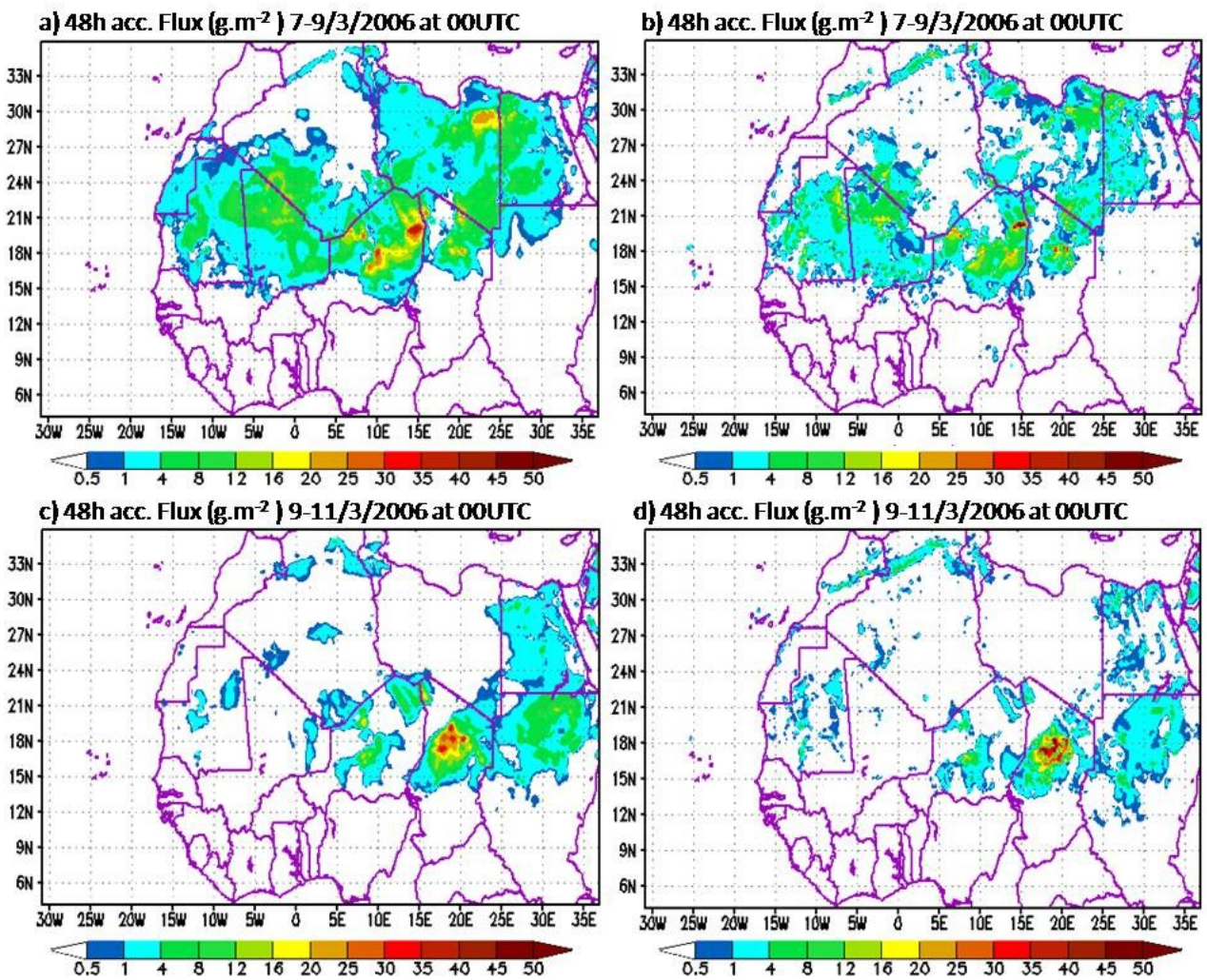

Fig. 16. 48-h accumulated dust fluxes (in $\mathrm{gm}^{-2}$ ) simulated by ALADIN with EXP3 (a) and (c) and EXP4 (b) and (d) for 7-9 March , 9-11 2006 and at 00:00 UTC.

were compared with the observations. The results are shown in Fig. 15.

Over Banizoumbou (Fig. 15a), the dust surface concentrations observed were high during the dust storm event, with a maximum reaching $4500 \mu \mathrm{gm}^{-3}$ on 9 March. 7 March marked the beginning of this episode with one observation of $2500 \mathrm{\mu gm}^{-3}$, but the concentrations simulated by EXP3 and EXP4 were under $1000 \mu \mathrm{gm}^{-3}$. The second peak was

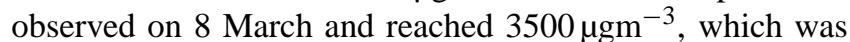
well simulated by EXP3, but EXP4 underestimated this peak.
The third peak, i.e. the maximum $\left(4500 \mu \mathrm{gm}^{-3}\right)$, was seen on 9 March. This peak was very well simulated by EXP4, whereas it was overestimated by EXP3. During this episode, THR seriously underestimated the dust concentration. After 10 March, EXP3 largely overestimated the concentration and EXP4 was in agreement with the observations.

Over Mbour (Fig. 15b), during the dust storm event, the THR configuration underestimated the surface concentration. 8 March marked the beginning of the episode over Mbour, where a peak around $1500 \mu^{-3}$ was observed. EXP4 
predicted a peak around $2500 \mu \mathrm{gm}^{-3}$ and EXP3 predicted a very high peak of around $5000 \mathrm{\mu gm}^{-3}$. The second peak around $2500 \mathrm{\mu gm}^{-3}$ was observed on 9 March and was very well predicted by EXP4 but was overestimated by EXP3. After 10 March, EXP4 was in good agreement with the observations but EXP3 overestimated the surface concentration.

\subsubsection{Surface dust flux}

In this section, $48 \mathrm{~h}$ of accumulated dust flux simulated by EXP3 (Fig. 16a and c) and EXP4 (Fig. 16b and d) for 79 March and 9-11 March 2006, at 00:00 UTC are compared. The lack of surface dust flux observations led to the consideration of only the difference between these two configurations in terms of spatial distribution and intensity in this comparison study. First, in terms of distribution, we observe that the region of dust emission provided by EXP3 is larger than that given by EXP4, especially on 7-9 March where EXP3 shows a continuous spatial field of dust flux over Libya, western Egypt, northern Niger, Mali, and Mauritania, while that found by EXP4 is scattered. In terms of intensity, the high values of the accumulated dust flux obtained by EXP3 and EXP4 are predicted over the dust source emission region represented previously. Between 7 and 9 March, EXP3 predicted 3 important cores of dust flux $\left(30-36 \mathrm{gm}^{-2}\right)$, all located over sandy soil, in north-eastern Libya and northeastern and central Niger, but EXP4 predicted one small core located in north-eastern Niger. On 9-11 March, EXP3 predicted one intense core of dust flux located in the Bodélé depression $\left(30-36 \mathrm{gm}^{-2}\right)$ but that provided by EXP4 was very intense $\left(40-45 \mathrm{gm}^{-2}\right)$. Studies based on simulations (Laurent et al., 2008; Tegen, 2002) and satellite observations (Brooks and Legrand, 2000; Prospero et al., 2002) show that the Bodélé region is a very intense dust source. This adds credibility to the results relating to the intense dust flux emission over this region simulated by EXP4.

\section{Conclusions}

This work provides a contribution to the development of the ALADIN model by introducing atmospheric dust aerosol as a prognostic tracer. The production and emission phases are simulated in the ISBA scheme integrated in SURFEX. To improve the dust emission in SURFEX, the DEAD scheme was revised. The choice of the relations and parameterizations used in this version were examined for compatibility with the soil and surface databases used in SURFEX. The comparative study conducted in 0-D showed that the Fécan formulation provided low threshold moisture and generated a high erosion threshold over all soils. The MaB95 formulation provided weak sandblasting efficiency, particularly over loamy sand and sandy loam soils. However, some studies consider these soils as an important dust emission source. Marticorena et al. (1997) used data from Chatenet et al. (1996) and Gillette (1979) to estimate the size distribution and fine particle content in the soil. These data were different from the FAO database and there was no correspondence between the fine particles used in MaB95 and the FAO clay contents. On the other hand, the revised DEAD reproduced the location of the dust sources and the erosion thresholds satisfactorily. This scheme points to loamy sand soil and sandy loam soil as important dust sources. These soils contain both large particles supporting saltation and fine particles available for suspension. This mixture of particles is favourable for sandblasting phenomena.

The 3-D simulations show that THR representation always underestimates the AOD and concentrations over all AERONET photometer stations. This underestimation is caused by the incompatibility of the theoretical formulation with the FAO and ECOCLIMAP databases. On the other hand, DEAD and revised DEAD predict reasonable AOD at the major stations. But an over-estimate of the surface concentrations is noted for DEAD. This over-estimation is due to the critical uniform sandblasting efficiency calculated with a clay fraction equal to $20 \%$ for all soil types. On the other hand, the revised DEAD satisfactorily predicts the surface concentrations and rigorously identifies the natural dust sources over Africa. These results justify the choice of the formulations used in this scheme and the representativeness of the natural dust emission by the relative surfaces.

Since, our study is based on a single event and a specific region, we are cautious about generalizing our conclusion to the global scale. This will require long simulations and evaluations by skill scores, which we intend to carry out in future work.

An important element that sensibly influences the dust emission is neglected in the revised DEAD: the temporal variability of vegetation cover in the dust source area (Shannon and Lunt, 2011). Another factor having an important influence in dust emission is not directly considered in the revised DEAD: the spatial variation of the aerodynamic roughness length (Laurent et al., 2008). Because of these limits, the revised DEAD remains, like the original, a scheme of intermediate complexity.

The modifications and changes introduced in DEAD have been included in SURFEX version 7.1 (http://www.cnrm. meteo.fr/surfex/).

Acknowledgements. The authors thank F. Ounnar (Director General of the Algerian Met Office), C. Fischer (LTM ALADIN/France), and B. Hamadache (Director of Forecasting). This work was supported by the Algerian Met Office (ONM), Météo France, Centre National de Recherches Météorologiques (CNRM), and the French Embassy in Algeria.

Edited by: O. Boucher 


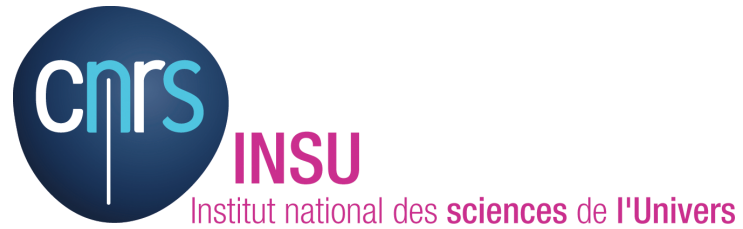

The publication of this article is financed by CNRS-INSU.

\section{References}

Alfaro, S. C. and Gomes, L.: Modeling mineral aerosol production by wind erosion: Emission intensities and aerosol distributions in source areas, J. Geophys. Res, 106, 18075-18084, 2001.

Berthet, S., M. Leriche, M., Pinty, J.-P., Cuesta, J., and Pigeon G.: Scavenging of aerosol particles by rain in a cloud resolving model, Atmos. Res., 96, 325-336, 2010.

Brooks, N. P. J. and Legrand, M.: Dust variability over northern Africa and rainfall in the Sahel, in Linking climate change to landsurface change, edited by: McLaren, S. J. and Kniveton, D., Chapter 1, Kluwer Academic Publishers, 1-25, 2000.

Bubnová, R., Hello, G., Bénard, P., and Geleyn, J. F.: Integration of the fully elastic equations cast in the hydrostatic pressure terrain following coordinates in the framework of the ALADIN NWP system, Mon. Wea. Rev., 123, 515-535, 1995.

Buckley, R. L.: Spatial Variation of Soil Type and Soil Moisture in the Regional Atmospheric Modeling System (U),WSRC-TR 2001-00119, March 2001.

Callot, Y., Marticorena, B., and Bergametti, G.: Geomorphologic approach for modelling the surface features of arid environments in a model of dust emission: application to the Sahara desert, Geodinamica Acta, 13, 245-270, 2000.

Chatenet, B., Marticorena, B., Gomes, L., and Bergametti, G.: Assessing the size distribution of desert soils erodible by wind, Sedimentol., 43, 901-911, 1996.

Crumeyrolle, S., Tulet, P., Gomes, L., Garcia-Carreras, L., Flamant, C., Parker, D. J., Matsuki, A., Formenti, P., and Schwarzenboeck, A.: Transport of dust particles from the Bodélé region to the monsoon layer - AMMA case study of the 9-14 June 2006 period, Atmos. Chem. Phys., 11, 479-494, doi:10.5194/acp-11479-2011, 2011.

Fécan, F., Marticorena, B., and Bergametti, G.: Parametrization of the increase of the aeolian erosion threshold wind friction velocity due to soil moisture for arid and semi-arid areas, Ann. Geophys., 17, 149-157, doi:10.1007/s00585-999-0149-7, 1999.

Geleyn, J. F.: Adaptation of spectral methods to non-uniform mapping (global and local), ECMWF Seminar Proceedings on "Recent developments in numerical methods for atmospheric modeling", 7-11 September 1998, 226-265, 1998.

Gibelin, A. L.: Externalisation du schéma de surface Isba du modèle de circulation générale Arpège-Climat, Note de Centre du GMGEC no. 88, 2004.

Gillette, D. A.: Environmental factors affecting dust emission by wind erosion in Saharan dust, edited by C. Morals, 71-94, John Wiley, New York, 1979,

Grini, A. and Zender, C.: Roles of saltation, sandblasting, and wind speed variability on mineral dust aerosol size distribution during the Puerto Rican Dust Experiment (PRIDE), J. Geophys. Res., 109, D07, 202, doi:10.1029/2003JD004233, 2004.
Grini, A., Tulet, P., and Gomes, L.: Dusty weather forecasts using the MesoNH mesoscale atmospheric model, J. Geophys. Res., 111, D19205, doi:10.1029/2005JD007007, 2006.

Horányi, A., Ihàsz, I., and Radnoti, G.: ARPEGE/ALADIN: A numerical weather prediction model for Central Europe with the participation of the Hungarian Meteorological Service, idöjàràs, 100, 277-301, 1996.

Huth, R., Mlàdek, R., Metelka, L., Sedlàk, P., Huthová, Z., Kliegrová, S., Kysely, J., Pokorná, L., Halenka, T., and Janousek, M.: On the integrability of limited-area numerical weather prediction model ALADIN over extended time periods, Stud. Geophys. Geod., 47, 863-873, 2003.

Kocha, C., Lafore, J.-P., Tulet, P., and Seity, Y.: High-resolution simulation of a major West African dust-storm: comparison with observations and investigation of dust impact, Q. J. Roy. Meteorol. Soc., doi:101002/qj.927,2011.

Kok, J. F.: A scaling theory for the size distribution of emitted dust aerosols suggests climate models underestimate the size of the global dust cycle, Proc. Natl. Acad. Sci. U. S. A., 108, 10161021, doi:10.1073/pnas.1014798108, 2011.

Kok, J. F.: Does the size distribution of mineral dust aerosols depend on the wind speed at emission?, Atmos. Chem. Phys., 11, 10149-10156, doi:10.5194/acp-11-10149-2011, 2011.

Laurent, B., Marticorena, B., Bergametti, G., Léon, J. F., and Mahowald, N. M.: Modeling mineral dust emission from the Sahara desert using new surface properties and soil database, J. Geophys. Res., 113, D14218, doi:10.1029/2007JD009484, 2008.

Lopez, P.: Implementation and validation of a new prognostic large-scale cloud and precipitation scheme for climate and dataassimilation purposes, Q. J. R. Meteorol. Soc., 128, 229-257, 2002.

Mahowald, N., Kohfeld, K., Hansson, M., Balkanski, Y., Harrison, S. P., Printice, I. C., Schulz, M., and Rodhe, H.: Dust sources and deposition during the last glacial maximum and current climate: A comparison of model results with paleodata from ice cores and marine sediments, J. Geophys. Res., 104, 15895-15916, 1999.

Mallet, M., Tulet, P., Serça, D., Solmon, F., Dubovik, O., Pelon, J., Pont, V., and Thouron, O.: Impact of dust aerosols on the radiative budget, surface heat fluxes, heating rate profiles and convective activity over West Africa during March 2006, Atmos. Chem. Phys., 9, 7143-7160, doi:10.5194/acp-9-7143-2009, 2009.

Marticorena, B. and Bergametti, G.: Modeling the atmospheric dust cycle: 1. Design of a soil-derived dust emission scheme, J. Geophys. Res., 100, 16, 415-430, doi:10.1029/95JD00690, 1995.

Marticorena, B., Bergametti, G., Aumont, B., Callot, Y., N’Doume, C., and Legrand, M.: Modeling the atmospheric dust cycle: 2. Simulation of the Saharan dust sources, J. Geophys. Res., 102, 4387-4404, 1997a.

Marticorena, B., Bergametti, G., Gillette, D. A., and Belnap, J.: Factors controlling threshold friction velocity in semiarid and arid areas of the United States, J. Geophys. Res., 102, 23, 277 287, doi:10.1029/97JD01303, 1997b.

Marticorena, B., Chatenet, B., Rajot, J. L., Traoré, S., Coulibaly, M., Diallo, A., Koné, I., Maman, A., NDiaye, T., and Zakou, A.: Temporal variability of mineral dust concentrations over West Africa: analyses of a pluriannual monitoring from the AMMA Sahelian Dust Transect, Atmos. Chem. Phys., 10, 8899-8915, doi:10.5194/acp-10-8899-2010, 2010. 
Martin, J. H.: Glacial-interglacial $\mathrm{CO}_{2}$ change: The iron hypothesis, Paleoceanography, 5, 1-13, 1990.

Masson, V.: A physically-based scheme for the urban energy balance in atmospheric models, Bound.-Lay. Meteorol., 94, 357397, 3.1, 2000.

Masson, V., Champeaux, J., Chauvin, F., Meriguet, C., and Lacaze, R.: A global database of land surface parameters at 1-km resolution in meteorological and climate models, J. Climate, 16, 12611282, 3.2, 2003.

Mlawer, E. J., Taubman, S. J., Brown, P. D., Iacono, M. J., and Clough, S. A.: RRTM, a validated correlated-k model for the longwave, J. Geophys. Res., 102, 16663-16682, 1997.

Morcrette, J. and Fouquart, Y.: The overlapping of cloud layers in shortwave radiation parameterizations, J. Atmos. Sci., 43, 321328, 3.1, 1986.

Nicholson, S. E., Tucker, C. J., and Ba, M. B.: Desertification, drought, and surface vegetation: An example from the West African Sahel, B. Am. Meteorol. Soc., 79, 815-829, 1998.

Nickovic, S. and Dobricic, S.: A model for long-rang transport of desert dust, Mon. Wea. Rev., 124, 2537-2544, 1996.

Nickovic, S., Kallos, G., Papadopoulos, A., and Kakaliagou, O.: Model for prediction of desert dust cycle in the atmosphere, J. Geophys. Res., 106, D16, 18113-18129, 27 August 2001.

Noilhan, J. and Planton, S.: A simple parameterization of land surface processes for meteorological models, Mon. Wea. Rev., 117, 536-549, 1989.

Noilhan, J. and Mahfouf, J. F.: The ISBA land surface parameterization scheme, Glob. Plan. Change, 13, 145-159, 3.1, 1996.

Perlwitz, J., Tegen, I., and Miller, R. L.: Interactive soil dust aerosol model in the GISS GCM: 1 . Sensitivity of the soil dust cycle to radiative properties of soil dust aerosols, J. Geophys. Res., 106, 18167-18192, 2001

Prospero, J. M.: Long-term measurements of the transport of African mineral dust to the south-eastern United States: Implications for regional air quality, J. Geophys. Res., 104, 1591715928, 1999.

Prospero, J. M., Ginoux, P., Torres, O., Nicholson, S. E., and Gill, T. E.: Environmental characterization of global sources of atmospheric soil dust identified with the Nimbus 7 Total Ozone Mapping Spectrometer (TOMS) absorbing aerosol product, Rev. Geophys., 40, 1, 1-31, 2002.

Radnóti, G.: Comments on "A spectral limited-area formulation with time-dependent boundary conditions applied to the shallow water equations", Mon. Wea. Rev., 123, 3122-3123, 1995.

Shannon, S. and Lunt, D. J.: A new dust cycle model with dynamic vegetation: LPJ-dust version 1.0, Geosci. Model Dev., 4, 85-105, doi:10.5194/gmd-4-85-2011, 2011.

Shao, Y.: A model for mineral dust emission, J. Geophys. Res., 106, 20239-20254, 2001.

Shao, Y. and Leslie, M.: Wind erosion prediction over the Australian continent, J. Geophys. Res., 102, 30091-30105, 1997.

Shao, Y., Raupach, M. R., and Leys, J. F.: A model for predicting aeolian sand drift and dust entrainment on scales from paddock to region, Aust. J. Soil Res., 34, 309-342, 1996.
Shinn, E. A, Smith, G., Prospero, J., Betzer, P., Hayes, M., Garrison, V., and Barber R.: African dust and the demise of Caribbean coral reefs, Geophys. Res. Lett., 27, 3029-3032, 2000.

Slingo, A., Ackerman, T. P., Allan, R. P., Kassianov, E. I., McFarlane, S. A., Robinson, G. J., Barnard, J. C., Miller, M. A., Harries, J. E., Russell, J. E., and Dewitte, S.: Observations of the impact of a major Saharan dust storm on the atmospheric radiation balance, Geophys. Res. Lett., 33, L24817, doi:10.1029/2006GL027869, 2006.

Swap, R., Garstang, M., Greco, S., Talbot, R., and Kallberg, P.: Saharan dust in the Amazon Basin, Tellus, Ser. B, 44, 133-149, 1992.

Tegen, I. and Fung, I.: Modeling of mineral dust in the atmosphere: Sources, Transport, and optical thickness, J. Geophys. Res., 99, 22897-22914, 1994.

Tegen, I., Lacis, A. A., and Fung, I.: The influence on climate forcing of mineral aerosols from disturbed soils, Nature, 380, 419422, 1996.

Tegen, I., Harrison, S. P., Kohfeld, K., Prentice, I. C., Coe, M., and Heimann, M.: Impact of vegetation and preferential source areas on global dust aerosol: Results from a model study, J. Geophys. Res., 107, 4576, doi:10.1029/2001JD000963, 2002.

Tulet, P., Crassier, V., Cousin, F., Suhre, K., and Rosset, R.: ORILAM, a three-moment lognormal aerosol scheme for mesoscale atmospheric model: Online coupling into the MesoNH-C model and validation on the Escompte campaign, J. Geophys. Res., 110, D18201, doi:10.1029/2004JD005716, 2005.

Tulet, P., Mallet, M., Pont, V., Pelon, J., and Boon, A.: The $7-$ 13 March 2006 dust storm over West Africa: Generation, transport, and vertical stratification, J. Geophys. Res, 113, D00C08, doi:10.1029/2008JD009871, 2008.

Tulet, P., Crahan-Kaku, K., Leriche, M., Aouizerats, B., and Crumeyrolle, S.: Mixing of dust aerosols into a mesoscale convective system Generation, filtering and possible feedbacks on ice anvils, Atmos. Res., 96, 302-314, 2010.

United States Department of Agriculture (USDA), Natural Resources Conservation Service (NRCS), Soil Taxonomy : A Basic System of Soil Classification for Making and Interpreting Soil Surveys Agr. Handb. 436. U.S. Govt. Print.Office, Washington DC, 20402, 870 pp., second edn., 1999.

Váòa, F.: Physical parameterizations in the ALADIN model, Meteorol. zpr., 51, 33-44, 1998.

Zakey, A. S., Solmon, F., and Giorgi, F.: Implementation and testing of a desert dust module in a regional climate model, Atmos. Chem. Phys., 6, 4687-4704, doi:10.5194/acp-6-4687-2006, 2006.

Zender, C. S., Bian, H., and Newman, D.: Mineral Dust Entrainment and deposition (DEAD) model: Description and 1990s dust climatology, J. Geophys. Res., 108, D14, 4416, doi:10.1029/2002JD002775, 2003.

Zobler, L.: A World soil file for global climate modelling, Tech. Rep. NASA-TM-87802, 32 pp., 1986. 